Andrews University

Digital Commons @ Andrews University

2018

\title{
Activist Leadership: A Grounded Theory Study Of Leadership And Effective Public-Sector Performance In A Young Democracy
}

Akinwumi Oladapo Oke

Andrews University, oke@andrews.edu

Follow this and additional works at: https://digitalcommons.andrews.edu/dissertations

Part of the Leadership Studies Commons

\section{Recommended Citation}

Oke, Akinwumi Oladapo, "Activist Leadership: A Grounded Theory Study Of Leadership And Effective Public-Sector Performance In A Young Democracy" (2018). Dissertations. 1650.

https://digitalcommons.andrews.edu/dissertations/1650

https://dx.doi.org/10.32597/dissertations/1650

This Dissertation is brought to you for free and open access by the Graduate Research at Digital Commons @ Andrews University. It has been accepted for inclusion in Dissertations by an authorized administrator of Digital Commons@ Andrews University. For more information, please contact repository@andrews.edu. 


\begin{abstract}
ACTIVIST LEADERSHIP: A GROUNDED THEORY STUDY OF LEADERSHIP AND EFFECTIVE PUBLIC-SECTOR PERFORMANCE IN A YOUNG DEMOCRACY
\end{abstract}

by

Akinwumi Oladapo Oke

Chair: Jay Brand 


\title{
ABSTRACT OF GRADUATE STUDENT RESEARCH
}

\author{
Dissertation
}

\author{
Andrews University \\ School of Education
}

\section{Title: ACTIVIST LEADERSHIP: A GROUNDED THEORY STUDY OF LEADERSHIP AND EFFECTIVE PUBLIC-SECTOR PERFORMANCE IN A YOUNG DEMOCRACY}

Name of researcher: Akinwumi Oladapo Oke

Name and degree of faculty chair: Jay Brand, Ph.D.

Date completed: March 2018

\section{Problem}

The problem this study investigated is the phenomenon of a small but growing group of activist political leaders who are redefining public sector governance by reshaping the organizations they lead, thereby improving the institutional environments of hitherto moribund public agencies. The study explored the unique dispositions, skills, values, and/or behaviors of this class of leaders in order to provide an understanding of their emergence in terms of their development, decision-making and other personal leadership characteristics that evolved into their 'activist' nature. The purpose of this research was to develop a grounded theory regarding how the leadership competencies/qualities exhibited by this new breed of public sector leaders support the 
achievement of 'above-the-norm' organizational performance in the public sector, despite the constraints of weak governance institutions within their specified contexts. The study has its conceptual framework drawn from the notions of effective leadership from a personal leadership perspective, as described in the works of Greenstein (1979) and, Mumford (2006).

\section{Method}

The method of investigation adopted for this study was a 'grounded theory' approach (Strauss \& Corbin, 1994, p. 273), a general methodology of qualitative research designed to build substantive theory based on the systematic collection and analysis of data. Data collection was primarily by open ended narrative interviews with a purposive sample of seven public sector leaders who had been (a) identified by perceived improvement in organizational performance during their tenure in public office (b) their leadership activism as demonstrated in their use of public office to effect social change within their leadership context (c) held public sector leadership role for a minimum of three years (d) in leadership at national and/or sub-national levels and (e) validated by a subject matter expert. In addition, four (4) key informants were interviewed - who is either a past/present associate/subordinate of five (5) of the leader(s) interviewed in the study.

Results

Three major themes emerged from my interviews with the leaders: (a) their managerial and personal approach; (b.) their cognitive disposition to achieving good governance outcomes; and (c.) their pragmatic leadership approach to resolving leadership challenges of weak institutional contexts. These leaders are able to deliver 
effective leadership despite weak institutional/governance frameworks, not by using a specific leadership technique; but rather by manifesting their own personal convictions for achieving results — convictions that emerges from a matured conceptualization of their self-integration process.

\section{Conclusion}

The study concludes that leaders' personal characteristics, understanding of selfconcepts, and a pragmatic approach empower them to successfully create a compelling personal vision that has a clear ethical framework. They combine these with the capacity to use their social and emotional competencies to achieve results. The study further claims that producing leaders who successfully lead public organizations effectively is the responsibility of many parts of the "ecosystem" of public leadership. 
Andrews University

School of Education

\title{
ACTIVIST LEADERSHIP: A GROUNDED THEORY STUDY OF LEADERSHIP AND EFFECTIVE PUBLIC-SECTOR PERFORMANCE IN A YOUNG DEMOCRACY
}

\author{
A Dissertation \\ Presented in Partial Fulfillment \\ of the Requirements for the Degree \\ Doctor of Philosophy
}

by

Akinwumi Oladapo Oke

March 2018 


\title{
ACTIVIST LEADERSHIP: A GROUNDED THEORY STUDY OF LEADERSHIP AND EFFECTIVE PUBLIC-SECTOR PERFORMANCE IN A YOUNG DEMOCRACY
}

\author{
A dissertation \\ presented in partial fulfillment \\ of the requirements for the degree \\ Doctor of Philosophy
}

by

Akinwumi Oladapo Oke

APPROVAL BY THE COMMITTEE:

Chair: Jay Brand

Member: Shirley Freed

Member: Erich Baumgartner

External: Ruth Horton
Dean, School of Education

Robson Marinho 


\section{DEDICATION}

This dissertation is dedicated first and foremost to the Almighty God, the giver of all good and perfect gifts. Thereafter, dedicated to my adorable wife and friend, Yetunde for her push and pull through it all. To my children, Oluwatoni, and AniOluwa who were denied my full attention while I was on this academic pursuit. 


\section{TABLE OF CONTENTS}

LIST OF ABBREVIATIONS ................................................................. vii

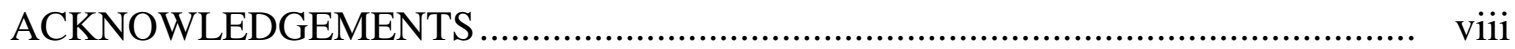

\section{Chapter}

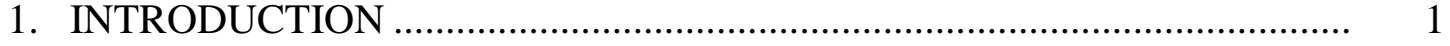

Leaders as 'Catalysts' ....................................................................... 2

Leaders as 'Activists' ....................................................................... 4

My Research Context.......................................................................... 7

Statement of the Problem....................................................................... 9

Purpose of the Study ............................................................................ 10

Research Questions ........................................................................ 10

Research Design.......................................................................... 11

Significance of Study ................................................................. 12

Basic Assumptions.......................................................................... 13

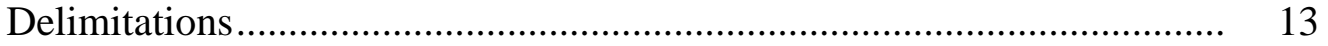

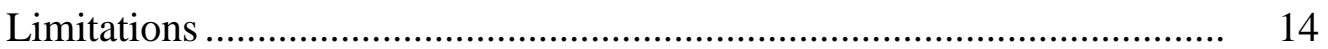

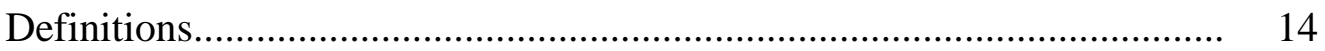

Research Outline ............................................................................. 15

2. REVIEW OF LITERATURE ................................................................. 17

Leadership and Organizational Performance...................................... 17

Leadership in the Public Sector ...................................................... 20

Public Sector Leadership and Governance Effectiveness........................ 28

The Activist Leader and Institutional Change in the Public Sector........... 31

Summary .............................................................................. 33

3. RESEARCH METHODOLOGY .......................................................... 35

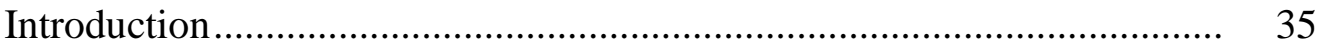

Research Question ....................................................................... 36

Research Design.......................................................................... 36

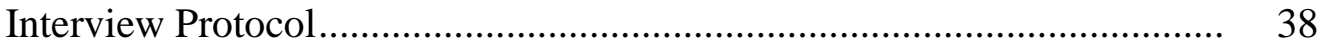

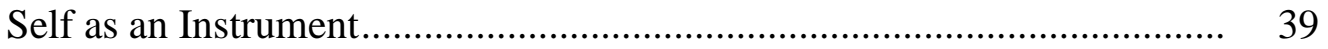

Purposive Sample......................................................................... 40

Data Collection ................................................................................... 43

Participant Interviews .......................................................... 43 


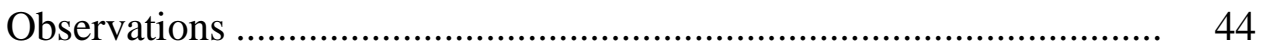

Key Informant Interviews ................................................................ 44

Review of Relevant Documents and Artifacts.................................... 45

Research Journal ..................................................................... 45

Data Analysis ................................................................................ 45

Validity Issues................................................................................ 47

Generalizability ....................................................................... 48

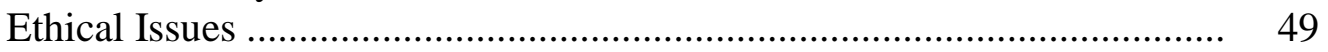

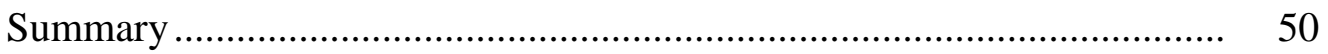

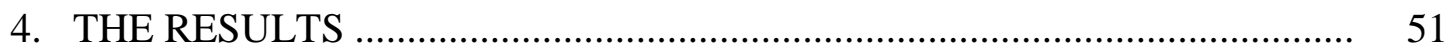

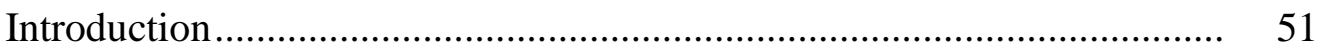

Research Participants ...................................................................... 51

Participants Profiles ……………………………………............... 52

Key Informant Profiles ................................................................. 53

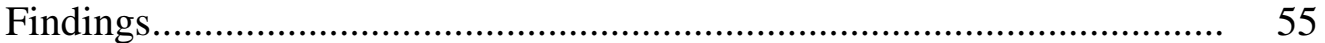

Leaders' Managerial and Personal Leadership Approach .................... 55

Competence.......................................................................... 55

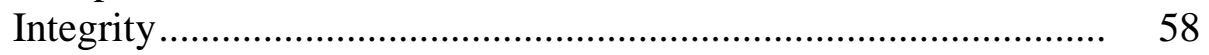

Resilient Capacity ..................................................................... 63

Leaders' Cognitive Approach Towards Achieving Governance

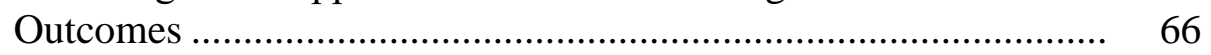

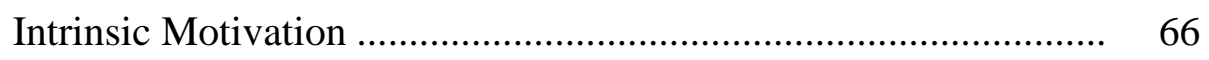

Achievement Focus...................................................................... 68

Leaders' Pragmatic Approach to Public Leadership ……………….... $\quad 72$

Innovation and Creativity in Leadership........................................ $\quad 72$

Institution Building Ability.......................................................... 76

Leaders as Effective Communicators and Motivators ................... $\quad 79$

Summary ……....................................................................... 83

Incidental Theme …………………................................... 82

5. SUMMARY AND RECOMMENDATIONS................................................ 85

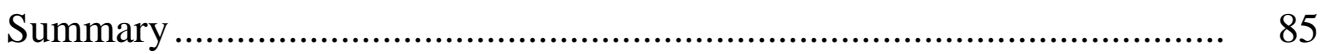

Research Design........................................................................ 86

Conceptual Lenses …………………………………………........ 86

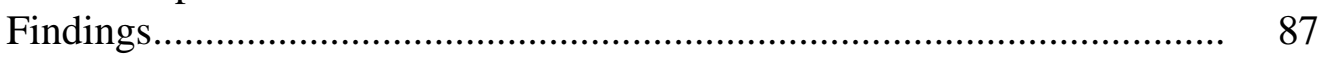

Discussion ................................................................................... $\quad 90$

Resonates with Concepts of Dulewicz, Mumford, Boyatzis, and

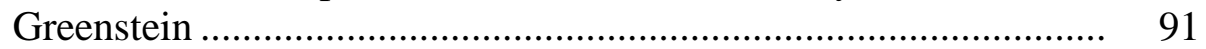

Leading with a Managerial and Personal Leadership Approach .... 91

Leading with a Cognitive Approach Towards Achieving

Governance Outcomes ......................................................... 96

Leading with Pragmatism ............................................................. 98

Resonates with Constructivist Developmental Theory ......................... 100 
Grounded Theory .......................................................................... 102

Achieving Effective Public Sector Leadership Performance in a

Young Democracy: A Grounded Theory..................................... 102

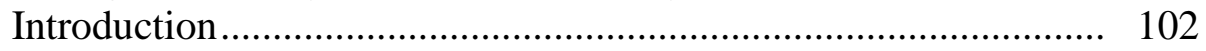

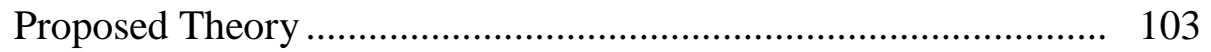

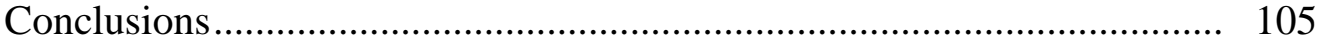

Recommendations ............................................................................... 106

Recommendations for Practice ........................................................ 107

Implications for Long-term Development of Public Sector

Leadership ......................................................................... 110

Recommendations for Further Research........................................... 112

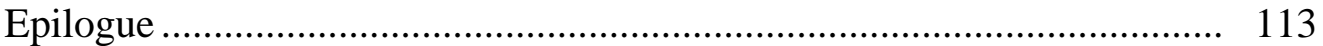

Appendix

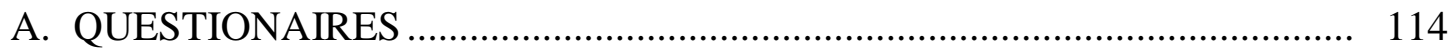

B. INTERVIEW QUESTIONS FOR KEY INFORMANTS .............................. 117

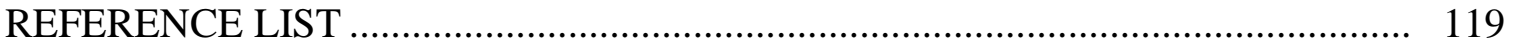

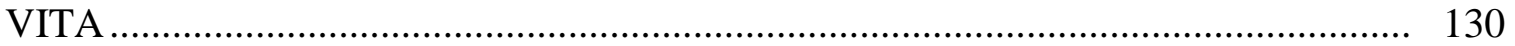




\section{LIST OF ABBREVIATIONS}

NGO - Non-governmental Organization

OECD - Organisation for Economic Co-operation and Development 


\section{ACKNOWLEDGEMENTS}

I could not have completed the doctoral journey without the help of several people who provided support and inspiration along the way. First, my deepest thanks and appreciation go to my dissertation committee led by Prof. Jay Brand for his constant coaching and guidance; Prof Emer. Shirley Freed and Prof. Erich Baumgartner for their thoroughness. Their criticism, feedback, and suggestions enriched this study. Also, a big thank you to Prof Emer. Sylvia Gonzalez; my faculty adviser at the commencement of the programme.

My special thanks to Pastor Cornelius Ayodeji Osuntade, his endearing wife - my sister Shayo; their children - Martins, Nelson and Oluwadunsin. Pastor Osuntade offered his home, time and resources during my stay on the Andrews University campus for the Annual Summer Conferences.

I like to thank my anonymous research participants and key informants who shared their public sector leadership experiences. These remarkable and patriotic Nigerian leaders created time out of their busy schedule to partake in the interviews. I am indebted to my associates who made it possible for me to meet with these leaders; worthy of special mention are Henry Adigun, Oyinda Adedokun, and Dr. Nguyan Feese. I appreciate the support of Dr. Joe Abah for his mentorship. His deep insights into Nigeria's governance challenges was invaluable to the success of this research. 
Finally, I am grateful to the following individuals: John Martin, Jake Ross, Dr. Philip Powell-Davies, Dr. Aderemi Oyewumi, Pastor Dipo Dada, Pastor (Dr.) Sunday Adelakin, Niyi Olaloku, Dr. Otive Igbuzor and Toyin Mayowa-Olalere.

To everyone mentioned above and the many not mentioned, I thank you all. 


\section{CHAPTER 1}

\section{INTRODUCTION}

Do leaders matter? This age-long question about the role of the individual leader in fostering positive organizational outcomes has been at the heart of leadership research for several decades (Jones \& Olken, 2005), and understanding the impact of effective leadership on the achievement of organizational objectives in both public and private sector organizations remains an important aim of contemporary leadership investigation. This quest for a better understanding of the role of effective leadership in organizations rests on two key principles or characteristics of effective leadership: (1) achievement of organizational goals is impossible without some form of sustained impulse provided by leaders (Elmuti, Minnis, \& Abebe, 2005), and (2) effective leadership is one of the key levers of influence upon which organizations rely for achieving their goals and objectives.

This considered view of effective leadership has been demonstrated in several ways and is associated with outcomes of the relationship between leaders, followers, and the context within which leadership is exercised (Agho, 2009; Burns, 1998). The observed catalytic effect of leaders on organizational members, especially through the use of a set of integrated transformational, transactional, and adaptive leadership behaviors is also well noted in leadership literature (Bass, 1997; Bass, Avolio, Jung, \& Berson, 2003; Cooper \& Nirenberg, 2012; Heifetz \& Laurie, 1997; Leavy, 2013). This association 
between leadership effectiveness and organizational outcomes was concisely defined in O'Reilly and Reed's (2010) "cascade of change narrative" by acknowledging the responsibility of leaders and leadership as the form of agency through which internal and external pressures are addressed and changes are outlined and championed in order to develop new services for meeting organizational objectives.

\section{Leaders as 'Catalysts'}

This view presupposes that leadership plays a crucial role in organizational achievement and achieving these organizational goals may sometimes involve changes in the organizational environment within which leaders lead. The question then arises as to how do individual leaders bring about positive change in public sector organizations, when operating within weak institutional environments? This is a pertinent question in view of the weak institutional environment of many developing countries, characterized by incomplete state building frameworks and fragile stability arising from an unresolved crisis of legitimacy (Osaghae, 2010).

The level of underdevelopment currently being experienced by most developing countries - including Nigeria, as a result of many years of elite hegemony — has been a major criticism of personal leadership theories as applied to leadership development in many developing countries. This is in view of the failure of past charismatic leaders in Africa to engender national cohesion and good governance outcomes through effective public sector leadership (Ake, 1966, p. 1). The resulting crisis of charismatic "legitimation and political integration" is responsible for the recent paradigm shift towards more institutionalized leadership by scholars of African political leadership. This call for an emphasis on building strong institutions, rather than strong leaders (Obama, 
2009) continues to be echoed by scholars and politicians throughout the continent and beyond, thereby appearing to ignore the potential role of personal leadership and its influence on public sector performance (Eisenstadt, 1970).

However, despite this characterization of the limitations of personal leadership for achieving and sustaining useful societal and political objectives, leaders may still potentially exert a profound influence for good or bad. The distinct complexity and interdependent nature of public sector organizations differentiates them from private agencies that often have a clear mandate to make money for shareholders, as well as from nonprofit firms (e.g., Non-Governmental Organizations [NGOs]) that also typically enjoy a relatively narrow range of goals. This differentiation provides an important aspect of the rationale for interrogating personal leadership in the public sector in difficult environments, where the definitions for success may be as varied as the opinions of individual citizens.

The influence of personal leadership in these contexts takes on a larger-than-life role when considered in terms of the enormous power these individuals wield to dispense patronage through their somewhat-unrestrained access and control of state power-often to the detriment of the larger society and interest of the common good. Political patronage in the form of "pork politics", endemic corruption through misappropriation, and misapplication of public funds in these contexts has been attributed to the strong leverage these leaders wield in young democracies in the absence of strong institutions of public accountability.

A better understanding of the associations between effective public sector leadership and good governance outcomes is therefore important due to the significant 
influence of the leaders' personal attributes in the exercise of leadership in these contexts. This has important considerations for achieving good public governance outcomes towards building strong institutions, as well as stable societies/economies in developing countries. These often ill-defined associations need to be understood particularly against the backdrop of the need for achieving sustainable improvements in citizens' lives, which remains a key challenge for many developing countries — countries that have poor governance systems and weak public sectors (Leonard, 2008).

\section{Leaders as 'Activists'}

In his universally acclaimed book, The Bottom Billion: Why the Poorest Countries are Failing and What Can Be Done About It, Paul Collier argues that "aid is often ineffective, and globalization can actually make matters worse" in the poorest nations

where institutions of governance are still evolving (p. 80). The panacea for the impending chaos and threat posed by these nations to the world can only be averted by devising significant changes to modern approaches towards public leadership and governance in these states.

The primal influence of the individual leader in public sector settings is especially pronounced in weak/dysfunctional governance contexts (Gray \& McPherson, 2001; Leonard, 1987) and has provided the impetus towards a public leadership agenda more focused on developing public sector leaders "who truly make a difference, who act as 'agents of change' to transform public problems into solutions that reflect a commitment to public values" (Getha-Taylor, Holmes, Jacobson, Morse, \& Sowa, 2011). However, despite this gloomy picture of developing countries as characterized by weak governance 
systems, there remains the question of why there have been examples of above-the-norm performance where the norm is inefficiency and failure of public sector agencies?

The complex leadership sphere in developing countries poses many challenges to achieving effectiveness for current and future public-sector leaders and calls for a new breed of leaders - the activist leader, as a kind of "atypical" leader recognized as a key factor for achieving sustainable improvements in governance (Abah, 2012; Goke, 2006; Grindle, 1997; Leonard, 1987, 2008; Thomas, 2008). The term "atypical”, in this sense, should not be interpreted as carrying any negative connotation, but as a reflection of leadership performance which is above the norm within its cultural and developmental context. This perspective explores the same conceptual vein as enunciated in similar research that investigated positive deviants of organization performance/effectiveness within weak governance environments (Abah, 2012; Agba, 2012; Leonard, 2008).

One important way this emerging class of leaders is reshaping public policy for the common good involves "facing down" entrenched, elite, political interests. This unusual willingness to confront the status quo is exemplified by a few public sector leaders who are willing to "go against the grain" by embracing reform in critical sectors of governance. They combine high technocratic acumen with transparency in governance by successfully implementing policies that promote the common good, despite facing deep-seated opposition in the form of resistance from powerful elite class interests, exposing corruption in high office, refocusing public expenditure away from patronage politics, and implementing tough reform policies to provide better access to public goods and services in a complex public leadership environment. 
These activist leaders in public sector organizations direct and energize the willingness of followers to achieve organizational goals and objectives (Abah, 2012) while influencing the political and cultural context within which they must operate (Leonard, 1987). The activist leader in most developing countries exercises leadership within a political and cultural context that is unresponsive to citizens, often corrupt and/or incompetent, and that may experience difficulty mobilizing resources and delivering public services to the citizens (Kaufmann, Kraay, \& Zoido-Lobatón, 2000). Activist leadership becomes even more important when considered within the context of political/executive leadership performance, which has been reported in relevant research literature as a critical factor in determining national economic growth and development (Jones \& Olken, 2005), sustainable change in public sector administration (Nabatchi, Goerdel, \& Peffer, 2011), governance effectiveness (Stoker, 1998) and overall public institutional performance or success (Jung \& Choi, 2011).

Although several studies have acknowledged the importance of leadership to the achievement of organizational goals, and "activist leaders" have been identified as an emerging class of leaders, especially in developing countries in Africa (Abah, 2012; Leonard, 2008), there remains a dearth of research in public sector leadership that fully explains how activist leaders in young democracies achieve atypical performance, despite the weak governance systems within which they operate. To fill this gap in the literature requires careful, further investigation of this set of leaders in developing countries who are able to initiate and sustain reforms in public agencies.

A better understanding of activist leadership in the public sector may also provide further valuable insights into why charismatic leadership alone has been insufficient for 
effectiveness as noted in African political leadership literature (Osaghae, 2010). This research therefore responds to current public sector leadership's shift from thinking about "leaders separate from their contexts, to thinking about leadership within the continuously changing context of a complex, adaptive inter-connected system" (Hartley $\&$ Benington, 2011) where an individual agency of leadership may activate positive institutional changes within the public domain.

\section{My Research Context}

Nigeria's nascent democracy represents an ideal context for my study, not only because it represents a developing country with weak governance systems, but also because it has a turbulent political leadership history that has left her in a state of being a nation with "low levels of national cohesion (one of the most deeply divided societies where conflict tends to be endemic and intractable), economic development and human security (this in spite of being one of the world's leading oil-producing countries), bad governance, political instability and state fragility" (Osaghae, 2010). The resulting scenario is reflected in the poor metrics of human development associated with the country. For instance, the 2013 Human Development Index report ranks Nigeria as one of the worst places to be born on the planet (Kekic, 2013). The report which utilized a set of "quality of life" surveys conducted in over eighty countries suggests that economic opportunity, health standards, and political freedoms are lowest in Nigeria when compared to the countries sampled.

Further evidence of the poor quality of governance in the country can be drawn from available data based on the Ibrahim Index of African Governance (IIAG). The Mo Ibrahim Foundation's IIAG awards the Ibrahim Index, which is an annual statistical 
assessment of the quality of governance in every African country. It is a highly respected barometer of how well African political leaders have provided "the political, social and economic goods that any citizen has the right to expect from his or her state, and that any state has the responsibility to deliver to its citizens" (Mo Ibrahim, 2007). The quality of leadership is assessed in four categories of governance effectiveness: safety and the rule of law, sustainable economic development, participation and human rights, and human development. In the 2015 rankings of over 100 countries in Africa, Nigeria ranked $39^{\text {th }}$ only a few places from the bottom of the Index where Somalia occupies the unenviable $54^{\text {th }}$ position.

In The Trouble with Nigeria (Achebe, 1984), foremost Nigerian novelist, poet, and social critic, Professor Chinua Achebe, stated emphatically that the "real problem with Nigeria is leadership". Achebe's assertion follows decades of failure by Nigeria's leaders (and ruling elite) to deliver on "the promises and challenges of independence, develop an appropriate political culture, good governance, economic development and national cohesion despite the country's abundant material and human resources" (Osaghae, 2010, p. 407). This acknowledged failure of leadership which dates back to the immediate post-independence era has led Nigeria through a civil war, seven military coups, and three unsuccessful attempts at democratic rule before the latest experiment that began in 1999, after it became clear that successive military leadership had failed to prove itself as a credible alternative to the civilian elite they repeatedly ousted for incompetence and corruption.

The return of democratic government in 1999, after decades of military rule, has ushered in a few leaders who are generally considered to be positive deviants of the 
norm, in terms of Nigeria's political elite. These leaders that emerged on the scene since 1999 appeared to have surmounted the challenges of weak-state institutions to achieve above-the-norm performance, and this research intends to explore the phenomenon of the "activist leader" in terms of identifying the leadership attributes/behaviors associated with activist leadership, as well as atypical leadership performance in public service delivery in a developing country context, using Nigeria's crop of activist leaders.

\section{Statement of the Problem}

Nigeria's transition from years of military rule to a democratically-elected government in 1999 led to the emergence of new public-sector leaders at every level of governance. These leaders face the challenges of delivering good governance outcomes within the weak institutional environments inherited from past military regimescharacterized by a culture of corruption and lack of accountability.

While many scholars of African political leadership have discounted the significance of personal leadership theories in achieving governance effectiveness and have argued for strengthening public institutions as a means of enhancing public sector performance and quality of governance (Botha, van Wyk, \& Swart, 2014), these studies fail to recognize the emergence of a set of altruistic leaders who are changing the political and institutional landscape of their weak governance environments, thereby strengthening the institutions they led. This is in view of the focus of these scholars on charismatic legitimation theory to explain the demand for heroic leadership in most developing countries - a focus that largely "ignored the contextual historical and social formation variables that relate to the character of the elites, their values, social basis, levels of 
coherence and cohesion, recruitment mode, attitudes, motivations, orientations and other variables, which differ from one country to another" (Osaghae, 2010, p. 412).

\section{Purpose of the Study}

This study aims to investigate the phenomenon of a small but growing group of Nigeria's activist political leaders who are redefining public sector governance by reshaping the organizations they lead, thereby improving the institutional environments of hitherto moribund public agencies. This qualitative research used the grounded theory approach to explore the unique dispositions, skills, values, and/or behaviors of this class of leaders in order to develop a theory of activist leadership. The resulting theory was based on an understanding of their emergence in terms of their development, decision making, and other personal leadership characteristics that evolved into their "activist" nature.

Their "activism" is defined in terms of the ability of these individuals to deliver above-the-norm organizational performance/effectiveness despite weak institutional/governance frameworks in many developing countries. This unusual leadership approach was situated within political leadership literature as an emerging counterintuitive change model for improving public institutions in weak governance environments.

\section{Research Questions}

The research explored the following central question: How do these activist leaders exercise leadership in a different way than what is practiced in their governance context? 
A number of sub-questions were deployed regarding how these leaders characterize their leadership within their context, especially their adoption of a more altruistic use of power and authority in a context widely regarded as lacking accountability. What kind of incentives/challenges do they face in the choices they made in order to achieve organizational goals higher than the context would normally expect? The study also sought to describe how these leaders have used political and administrative authority as the "primary holders, controllers and distributors of power and resources in a particular institution (i.e., institutional power) and/or territory" (Van Wyk, 2007, p. 5).

\section{Research Design}

The primary method of investigation was grounded theory, a qualitative research method designed to aid in the systematic collection and analysis of data and the construction of a theoretical model (Corbin \& Strauss, 2014). This approach generated a plausible framework for a theory of activist leadership by identifying themes using transcribed data from semi-structured, in-depth interviews with activist leaders and other participants in the study (including facilitated key informant interviews and documentary evidence); these data were analyzed for concepts and context.

The analysis identified patterns and a conceptual picture of how the selected participants describe the competencies of an activist leader and how these influenced atypical performances in the organizations they led. The theory articulated the interrelationships among the leadership themes exhibited by effective leaders in weak governance, public sector environments. 


\section{Significance of Study}

The urgent need for effective public-sector leadership in transition countries and young democracies has significant implications for improving the human condition in these countries. This is based on the acknowledgement of the nexus between leadership failure in these countries and the prevalence of corruption, poverty, preventable diseases (Ebegbulem, 2012; Kebonang \& Kebonang, 2013; Ogbeidi, 2012), and transnational terrorism (Piazza, 2008) that has now emerged as a threat to the entire global community.

This research hopes to provide a better understanding of personal leadership in the public sector which may hold important considerations for current and future public sector leadership development; it also provided empirical exploration of the nature of effective public leadership and its relationship to performance in weak governance states-especially how these leaders might contribute to strengthening public institutions (Bahnareanu, 2012; Gray \& McPherson, 2001; Organisation for Economic Co-operation and Development, 2001; Taylor \& Nel, 2002).

Ultimately the outcomes of this study may promote a leadership development model that public institutions can nurture as they aim to develop new leaders in developing countries, as well as to transform public institutions (Abah, 2012; Adegoroye \& Zealand, 2006; Afegbua \& Adejuwon, 2012). The envisaged transformation in leadership effectiveness will undoubtedly impact positively on the delivery of good governance outcomes, and for building better societies in weak governance environments whose citizens currently bear the brunt of the effects of ineffective leadership. It is hoped that the findings from this research may also be a useful resource base for national policy development institutes and public-sector leadership development professionals. 


\section{Basic Assumptions}

The following assumptions are made in conducting this study. First, that the identified activist leaders in national and sub-national public agencies have developed a set of identifiable activist leadership behaviors prior to their appointment into public service organizations. A second assumption is that activist leaders have an intrinsic motivation to participate in this study, and a third assumption is that subordinates of activist leaders are able to recognize this type of leadership and its role in and influence on organizational performance.

\section{Delimitations}

The activist leaders identified for the study were chosen for their leadership effectiveness as measured by the effective performance of their organizations. Relevant performance measures were based on improvements in quantity and quality of public services delivered to citizens through the agencies they currently lead or in the first fifteen years of democratic rule in Nigeria.

The selected individuals in this study have led Nigerian public-sector organizations at national and sub-national levels and theoretically operate within similar political and economic contexts across the six geopolitical zones of the country. This made it possible to assess somewhat systematically the internal and external factors that determine the consistent performance/effectiveness of their leadership.

The study is focused on only one country in order to understand the phenomenon of activist leadership within the same institutional context. By focusing on the same country, the study explored the pertinent phenomena in a defined political and institutional context. However, findings from the study have wider relevance in other 
countries with similar public-sector governance and institutional characteristics, thereby making the outcomes of this research a useful contribution to the literature.

\section{Limitations}

Due to the restricted criteria of this study on activist leaders in public sector organizations in a developing country, the available number of participants who fit the criteria was considerably delimited. However, this limitation does not in any way diminish the considerable impact of the findings from this study.

\section{Definitions}

Activist Leaders - The term activism in leadership is used to refer to three attributes that in fact may vary independently of one another: sheer extent of activity of the leader, commitment to use the office so as to have an impact on public policy, and actual success in affecting policy (Greenstein, 1979; Majumdar \& Mukand, 2010). Activist leaders are identified in this study as those individuals who have demonstrable achievement of organizational goals higher than leaders in similar operational contexts within the Nigerian public sector leadership sphere. The subjects of this study were differentiated on the following criteria: their personal commitment to the use of their office for improving the quantity and quality of public goods/services, as well as quantified success in terms of organizational output and outcomes based on verifiable data from the Nigerian National Bureau of Statistics.

Atypical Organizational Performance-Organizational performance that is better than the norm, rather than worse than the norm, for its operating context. "Atypical organizational performance" is used in the context of similar organizations in the same environment and is not used in the sense of global comparability across different 
environments (Abah, 2012). Atypical performance with regards to the quantity and quality of public goods/services, as well as quantified success in terms of organizational output and outcomes based on verifiable data from the Nigerian National Bureau of Statistics.

Dysfunctional/Weak Governance States - Nation states that are unresponsive to their citizens, corrupt, incompetent, and have difficulty mobilizing resources and delivering services to the poor (Kaufmann et al., 2000; Leonard, 2008; WorldBank, 2004).

Developing Countries - A developing country is one in which the majority lives on far less money — with far fewer basic public services - than the population in highly industrialized countries. Incomes are usually under \$2 per day and a significant portion of the population lives in extreme poverty (under $\$ 1.25$ per day) (WorldBank, 2013).

Good Governance-The capacity of government to formulate and implement sound policies in order to deliver or ensure the delivery of services to its citizens (WorldBank, 2004).

Leadership Effectiveness - The successful exercise of personal influence by one or more people that result in accomplishing shared objectives in a way that is personally satisfying to those involved (Cooper \& Nirenberg, 2012).

Organizational Effectiveness - An organization is said to be effective when it is successful at meeting organizational goals (Robbins, 1996).

\section{Research Outline}

This study aims to explore activist leadership as a counterintuitive approach to effective leadership performance in a young democracy context in which public sector 
leadership has weak institutional frameworks for accountability and is normally characterized by poor performance in terms of the governance outcomes. These activist governance outcomes include improvements in quality and quantity of public goods and services to citizens. The focus of this study was to develop a grounded theory that describes how such leaders are able to achieve effectiveness in delivery of organizational mandates that have resulted in organizational performances considered to be above the norm within the leadership/governance context.

The next chapter provides a short literature review focusing on public sector leadership and organizational performance by highlighting the nexus between public sector leadership and governance effectiveness. The review also provides a summary of interactions between activism in public sector leadership acting as an impetus for institutional change, as observed in various contexts by exploring these themes across global leadership domains in developed and developing countries.

The third chapter describes the methodology of the study, including research design, research question, research instrument, purposive sample, data collection, and data analysis. It also includes a discussion of validity issues, generalizability, and ethical issues.

The fourth chapter reports the results of the research and explores the leadership themes that seem to have emerged from the research.

The final chapter provides a summary of the research design, any emergent conceptual model of activist leadership, as well as other findings of the study. It will also offer a discussion of the findings, recommendations for practice, and recommendations for further research. 


\section{CHAPTER 2}

\section{REVIEW OF LITERATURE}

\section{Leadership and Organizational Performance}

Leadership is such a complex phenomenon that it was famously described by James McGregor Burns as "the most studied and least understood phenomenon on earth" (Burns, 1998). Burns's statement is likely borne out of the fact that effective leadership as an exercise of influence is a highly contextualized and relational construct (Day, Harris, \& Hadfield, 2001), which requires the alignment of the leaders' motives, means, and opportunities available to effect positive organizational outcomes (Boyne \& Dahya, 2002) within a given organizational environment.

Effective leadership in both private and public spheres has long been associated with organizational outcomes. This widely recognized role of the effective leader in organizations has led scholars to describe leadership as the glue that pulls together the resources required to bring about effective organizational performance (Majumdar \& Mukand, 2010), effective organizational performance being a measure of desired effectiveness (outcomes) and efficiency (outputs) in resource allocation and utilization within the organization (Organisation for Economic Co-operation and Development, 1996). This view of leadership remains deeply entrenched in leadership scholarship, despite the complexity in measures of leadership noted in Burn's assertion quoted above. 
In exploring the link between leadership and organizational performance, there appears to be no generally acceptable measures of the effect of leadership on organizational performance, due to the varying impacts of internal and external influences on both leadership and organizational performance (Joyce, 2009). Most of the recent available empirical studies on leadership effectiveness in organizations has been focused on the critical factors relevant to the organizational context in both public and private sector organizations (Ashworth, Boyne, \& Entwistle, 2010), such as followership (Agho, 2009; Katzenbach \& Smith, 2015; Kellerman, 2012; Majumdar \& Mukand, 2010) and other organizational environment factors (Afegbua \& Adejuwon, 2012; Dhar \& Mishra, 2001; Göran \& Wood, 2005).

This is somewhat of a paradox when considered in the light of leadership scholarship's chequered history, which was once annotated by theories developed from individual leadership traits, behaviors, and styles as determinants to organizational performance (Van Wart, 2009). The gradual transition to more inclusive research into leadership effectiveness is not unconnected with the emergence of the more multifaceted leadership theories articulated by James McGregor Burns (1998) regarding transformational and transactional theories.

Subsequent developments in integrative leadership models and the resulting romance of leadership - a tendency to over-attribute organizational outcomes to leadership (Meindl \& Ehrlich, 1987)—has subjected the leader-centric approach of earlier leadership research to debate due to emerging evidence challenging this view in the leadership research literature. The resulting lack of consensus among leadership scholars on a consistent role for leader effectiveness in organizational performance has 
led to a conclusion that leadership and organizational performance/effectiveness is a balancing act of competing demands, which are reflected in differing views of effectiveness (Pounder, 2002).

However, despite this attempt by some scholars to moderate the impact of the leader on organizational effectiveness, it is worth noting that the individual leaders' effectiveness still remains crucial to organizational effectiveness. This is especially pronounced in certain industries where leaders have exerted a high level of influence on their organizations in bringing about significant positive change. Leaders in global corporations or highly diversified organizations characterized by flat hierarchies and selfmanaging teams have been identified as 'Superleaders' — leaders who are leading others to lead themselves (Manz \& Sims Jr, 1991).

In the most simplistic definition, organizational effectiveness refers to the successful achievement of goals (Abah, 2012), and within the leadership/organizational development domains, leadership effectiveness has been described as the successful exercise of personal influence by one or more people that results in accomplishing shared objectives in a way that is personally satisfying to those involved (Cooper \& Nirenberg, 2012). Kanungo and Mendonca (1996) extended this assumption by introducing the ethical dimension into leadership effectiveness when they stated that "organizational leaders are truly effective only when they are motivated by a concern for others, when their actions are invariably guided primarily by the criteria of the benefit to others even if it results in some cost to oneself" (p. 35).

These variations in definitions have led to considerable disagreement on the approach of most leadership scholars in defining leadership in terms of organizational 
outcomes, and Ancona, Malone, Orlikowski, and Senge (2007) argued that this has produced problematic interpretations in various contexts because leadership can occur without explicit evidence of its outcome. Ancona and colleagues' assertion is in view of findings from empirical studies in educational settings, highlighting the fact that leadership effects are primarily indirect and often supported by other strong contingent factors within the organizational context (Pashiardis, Brauckmann, \& Muijs, 2011).

Further evidence within the political/executive leadership domain indicates that because leadership effects on organizational performance are not directly felt on the shop floor, there may be gaps in understanding the role of leadership in national development. Jones and Olken (2005), in their study of developing countries that have experienced sudden changes in national leadership, argued that despite the acknowledgment of the role of leadership as a causative force in economic growth and development, there still exists a need to characterize the impact of individual leadership transitions associated with shifts in national growth rates.

The foregoing conceptual landscape suggests that leadership rhetoric in this vein recognizes a relationship between leadership and organizational effectiveness, which is often set in the light of organizational performance, thereby assuming that organizational leaders are truly effective only when they deliver set organizational objectives.

\section{Leadership in the Public Sector}

A good understanding of leadership styles and their use within various contexts is of paramount importance, especially when considered in light of the contextual focus of leadership research, which has largely been the private sector. Research into individual leadership styles in the public sector still remains far less extensive than the available 
literature on the private sector, despite significant public sector leadership literature (Jones \& Olken, 2005). This is more so due to the public sector leadership studies' earlier lack of conceptual focus, arising from the loose definitions of leadership, which included a broad spectrum of management topics ranging from organizational change management to more implicit distinctions between administrative leadership and political/executive leadership (Montgomery Van, 2003).

The first set of empirical studies in public sector settings began to appear in leadership literature in the 1960s, led by (Guyot, 1962) in Government Bureaucrats are Different. Guyot's study was the first to identify the variations in the motivation of public and private sector leaders. Selznick (1984) expanded this theme further by stating that the public executive becomes a statesman as s/he transits from administrative management to institutional leadership in the course of a public service career.

Selznick's emphasis that the public sector was not just an organizational unit, but also an institution that draws on the organic evolution of public service, as it navigates the exigencies of its cultural and social contexts in delivering on its formal charter. While a public service organization is designed as a technical instrument for mobilizing resources towards achieving set goals, it evolves into an institution by responding to the social needs and pressures of its environment (p. 5).

This theme by Selznick became the rallying point for the introduction of transformational and charismatic leadership in public sector leadership development, despite the dichotomy between administrative leadership and political leadership that continues to define the narrative within public leadership, and may be responsible for the slightly divergent expectations of the two groups of leaders. The dichotomy of approach 
has meant that public sector leadership literature has applied a different lens on each type of leader within the public sphere-a "task-people" orientation for administrative leaders (Katzenbach \& Smith, 2015) and a "change leader" focus for political/executive leadership (Kotter, 1990).

The resurgence of interest in public sector leadership is not unconnected with the global drive for reform in many public agencies. New emerging trends on distributed, entrepreneurial, stewardship are gaining traction in the public sector after their acceptance in the private sector leadership domain (Adegoroye \& Zealand, 2006; Ashworth et al., 2010). The normative debate arising from the foregoing implies that for public sector leaders to be effective, they are constantly in a balancing act of determining the right amount and use of more activist leadership styles in achieving organizational effectiveness (Montgomery Van, 2003, p. 224).

The implications of this complex relationship between leadership and organizational performance in the public sector is further highlighted in the three dominant theories of effective leadership in the domain. The first focuses on the individual leaders' personality/competencies; the second group of theories are based on the type of influence activities employed by the leader; and a third set of theories are concerned with the interactions between political and managerial leaders in a shared leadership function (Ashworth et al., 2010).

Organizational outcomes observed in relation to the successful integration of leadership behaviours has led leadership scholars to associate effective leadership with both objective and subjective measures of leadership and organizational outcomes (Summermatter \& Siegel, 2009). Consequently, this association has been measured using 
objective measures such as financial performance indicators-profits, market share, return on investment, etc. (Chemers, 2000; Cooper \& Nirenberg, 2012; Dhar \& Mishra, 2001; Meindl \& Ehrlich, 1987)—while other scholars have used subjective measures such as employee morale and commitment to organizational goals, attitudes and perceptions of peers, etc. (Dhar \& Mishra, 2001).

It is pertinent to note that the factors involved in effective public-sector leadership have received increased attention among leadership scholars in recent years due to the need for a better understanding of the possible distinctions among public, private, and not-for-profit leadership (Pinnington, 2011). Since private, for-profit corporations can be understood as having a clear mandate - make money for shareholders—and nonprofit firms (e.g., NGOs) also typically enjoy a relatively narrow range of goals, these leadership contexts may face saliently distinct challenges from those faced by leaders in the public sector, where the definitions for success may vary widely.

A recurring theme in all of the foregoing is that these are all instances of goal achievement for which leadership has been observed to play a key role. This focus on goal achievement as an organizational outcome related to leader effectiveness also draws support from Stogdill's definition of leadership, which includes influencing the activities of an organized group towards goal achievement. This somewhat idealistic view captures the essence of leadership in the public domain because one of the most important outcomes of public leadership is improved public services - a clear instance of goal achievement - and this is in line with the common belief that public organizations are driven by the influence of the individual at the top. 
Although goalsetting and achievement remain key objectives of leadership (Stogdill, 1950, p. 4), the dual nature of public sector leadership—arising from the shared leadership responsibilities for both elected and appointed officials - places a more complex demand on public sector leaders. Van Wart (2003) further posits that this demand on leaders in the public sector ends up in a mutually exclusive choice between focusing on either "the ends (getting things done), the means by which things get done (the followers), or aligning the organization with external needs and opportunities (which can result in substantive change)". Both administrative (appointed) and political (elected) leaders face these choices in their daily interactions within a shared leadership paradigm that characterizes public leadership (p. 221).

Getha-Taylor et al. (2011), in an attempt to situate public sector leadership within its broader, societal context, further defined three main domains within this leadership genre - the character, function, and jurisdiction of public leadership. These were identified in relation to the ethics, obligations, and boundaries of leadership within which leaders must define their motives and secure the means to explore opportunities for the public good. This balancing act often results in what has been referred to as the "public service bargain"- a continuous but implicit understanding between political and administrative leaders on who has responsibility and entitlement for any course of leadership decision (Hood, 2002, p. 318 as cited in Asworth et al. 2010. p 85).

The constrained nature of public sector leadership, as a result of its requirement for democratic accountability, the rule of law, and due process, further complicates these interrelationships. This often implies that effective leaders in the public domain demonstrate an uncanny capacity to influence public service performance and 
improvements that fit their context (Ashworth et al., 2010). These contexts are increasingly characterized by the rising demand that leadership provide for the common good, with a purpose of creating public value while utilizing a boundary-spanning leadership approach towards the responsibilities associated with maintaining the public trust (Getha-Taylor et al., 2011).

This increasing demand for public accountability is an important element of vibrant democratic governance from which public leadership derives its credibility. While democracy has made the shared leadership paradigm difficult for public sector leaders, the increasing access to public leaders through the media, and especially through freedom of information legislation, has made it quite easy for the public to evaluate and influence leadership (Van Wart, 2003). The resulting scenario puts public sector leaders on trial, more so than other types of leadership (Avolio, Walumbwa, \& Weber, 2009; Ciulla, 2004; Summermatter \& Siegel, 2009). The leaders' ethics and actions are constantly scrutinized in the light of public opinion, and these additional pressures in the form of democratic accountability, respect for the rule of law, and due process have been observed to exert significant impact on the effectiveness of leadership in this domain (Ashworth et al., 2010).

Leadership in the public sector must also address a multiplicity of goals within its domain - a situation that ends up in goal conflict, especially in public agencies where enforcement and service functions are combined (Ashworth et al., 2010). Unlike the private sector, public sector leaders are often confronted with conflicting goals (Rainey, 1993 as cited in Ashworth et al., 2010) arising from a duty to enforce the law while taking reasonable care not to alienate citizens for whom the laws were enacted to protect. 
This places a higher level of constraint, represented by various legal and constitutional demands, on public-sector leaders in the exercise of leadership.

Another confounding factor in the public-sector leadership dilemma is the lack of consensus on a set of universal measures of performance among scholars and other stakeholders of public leadership (Summermatter \& Siegel, 2009). As Summermatter and Siegel (2009) reviewed the subject, they noted that although performance (and measures of it) in the public sector is an ambiguous, multidimensional, and complex concept, there are two main classes of leadership performance measures - output and outcome measures. These two relate to the public agencies' organizational efficiency (output) and effectiveness (outcome) measures respectively (Organisation for Economic Co-operation and Development, 1996).

Perry, Hondeghem, and Wise (2010) have described the outcomes of effective public-sector leadership in terms of the ease of access and quality of public goods and services received by citizens. These desired outcomes of public sector leadership, hinged on improved public management, involve better service delivery toward improving citizens' lives. A public sector leader is therefore deemed effective when s/he provides good public services, a clear sense of policy direction by articulating a vision, and support for an institutional framework that encourages creativity and nurtures innovation. This is the most compelling view of what effective public sector leadership represents (Montgomery Van, 2003) because it incorporates the achievement of good public governance (Organisation for Economic Co-operation and Development, 2001), a significant outcome of leadership in the public sphere. 
These key elements of public sector leadership_-its dual nature related to the need to harmonize elected and appointed roles, the complexity of its context arising from a requirement for public accountability, and the multiplicity and ambiguity of goals it aims to achieve - set it apart from other types of leadership (Ashworth et al., 2010, p. 80) as a more complex form. All the above-mentioned elements seem to suggest that leaders in the public sector face peculiar challenges in delivering organizational outcomes in an unpredictable environment, and the consequences of leadership have significant implications for society on a scale incomparable to private sector leaders and organizations.

The lack of a clear understanding of the relationships between effective publicsector leadership and efficient delivery of public goods has led many scholars to conclude that the art and practice of public-sector leadership in contemporary times can at best be described as a world of "complex changing interactions among individuals, agencies and organizations characterized by instability, uncertainty, fluctuation and change" (Kiel, 1994). In his seminal work on Chaos Theory as applied to public management, Kiel (1994) further noted that leadership in the public sector is in a state of constant flux, within which leaders are unable to predict the outcomes of their actions.

It is this identified need for good public governance that has led to the commitment of significant resources towards public-sector reform in many developing countries, with the aim of improving governance effectiveness as measured by improvements in key human development indicators (Acemoglu \& Jackson, 2011). 


\section{Public Sector Leadership and Governance Effectiveness}

In applying the propositions enumerated above and linking Chaos Theory to public-sector management, Kiel (1994) presented a view of leadership in the public sector as in a state of constant flux, within which leaders are unable to predict the outcomes of their actions. This approach recognizes the need for a new paradigm in public sector leadership and promotes a new reality that leaders have to be catalysts for change in an increasingly complex governance environment.

Leadership as a critical component of good public governance (Organisation for Economic Co-operation and Development, 2001) is intricately woven into a web of interrelationships among factors of efficient public administration. The relationship between leadership and governance is important for delivering the objectives of public sector institutions, and this is the essence of governance effectiveness (Stoker, 1998). Perry et al (2010) described effective public sector leadership in terms of the ease of access and quality of public goods and services received by citizens. This desired outcome of public-sector leadership is similarly termed, governance effectiveness.

The term "governance" evolved out of the public service reform movement of the 1980s in the United States, United Kingdom, and most of the developed economies. It describes the way in which the underlying values of a nation (usually articulated in some way in its constitution) are institutionalized (Organisation for Economic Co-operation and Development, 2001). Good governance has also been defined by the capacity of the government to formulate and implement sound policies in order to deliver or ensure the delivery of services to its citizens (WorldBank, 2004). 
As part of the World Governance Index, the WorldBank adopted six dimensions of governance: voice and accountability, political stability and absence of violence/terrorism, government effectiveness, regulatory quality, rule of law, and control of corruption (Kaufmann, Kraay, \& Mastruzzi, 2009; WorldBank, 2004). These indices of governance have since been deployed as a means of categorizing nations in terms of how leadership outcomes have impacted the social and economic development of citizens.

Critics of these dimensions of governance effectiveness and its indicators have noted that it lacks "construct validity" as a measure of governance across cultures and stages of national economic development, because the methodology of its formulation ignored large standard errors in its computations. This major limitation has been noted in governance literature (Thomas, 2009), although the term and its usage remain significant themes in governance and economic development research.

Despite the proliferation of the governance concept in the broader academic and practitioner literature, there is little agreement on definitions, scope, and what actually constitutes governance. This is arguably due to the fact that empirical research on the topic, with some exceptions, is generally limited to case studies without use of any common, conceptual framework for the term (Ruhanen, Scott, Ritchie, \& Tkaczynski, 2010).

There appears to be a consensus that governance is about developing effective coordination mechanisms between public-sector institutions and private-sector actors for understanding the constantly changing processes of administering/managing the production and distribution of public goods and services (Stoker, 1998). 
Stoker (1998) proposed five aspects of governance:

1. Governance involves actors drawn from within and outside government.

2. Governance recognizes the blurring of boundaries between public and private institutions for tackling economic and social issues.

3. Governance identifies the power dependencies involved in the relationships between institutions.

4. Governance includes and involves the activities of autonomous, self-governing actors.

5. Governance recognizes that governments' capacity to get things done does not rest solely on the authority of the state.

These five aspects, when studied in the light of the linkages between the two sets of leaders in the public sector domain - the administrative leaders (administrators of the government bureaucracy) and elected officials (political/executive leadership)—reveal a need for a different type of leadership style in order to link the two sets of leaders towards a common goal (Peters \& Helms, 2012).

This need to harmonize the objectives of public-sector leadership requires a leadership approach that can successfully navigate the increasingly complex and demanding nature of modern, public-sector governance. A review of literature in public administration and political science has revealed that this subject remains underdeveloped and therefore requires a better understanding of how contemporary governments operate for effective service delivery (Peters \& Helms, 2012). 


\section{The Activist Leader and Institutional Change in the Public Sector}

The term "activism in leadership" "refers to three attributes that in fact may vary independently of one another: sheer extent of activity; commitment to use public office so as to have an impact on public policy; and actual success in affecting policy" (Greenstein, 1979, p. 577). Greenstein's definition describes executive/political leadership and how effective leaders shape governance through their use of state institutions.

Studies in the political/executive leadership context have further identified several factors of activist leadership and their relationship to effective leadership. Goethals (2005) described high levels of activity, intelligence, optimistic resilience, flexibility, and opportunity as critical success factors for presidential leadership in the American context.

Activist leaders combine the roles of a transformational leader (Majumdar \& Mukand, 2010), administrator (Montgomery Van, 2003), conservator, and social entrepreneur by drawing on the psychological bases of leadership (Bahnareanu, 2012). The essence of these psychological principles of leadership is observed in the relational and transactional leadership theories. The effective use of these principles forms the bedrock of activist leader effectiveness and has been identified in research as a key characteristic of activist leaders (Bahnareanu, 2012).

In exploring the psychological principles of leadership theory, the effectiveness of activist leaders has been studied largely in relation to their relationship with followers. Zhihong, Wei, and Xiaoying (2013) described effective activist leadership in the public sector as a group concept which happens in a "process of affecting, a power of public spirit, a movement to common goals, and a direction to organization development" (p. 
74). However, the sparse literature on the subject of activist leadership also includes suggestions that it is very much an individual role with specific characteristics/traits adapted to leading organizational effectiveness (Abah, 2012, p. 315).

Leadership in the public sector is aimed at promoting institutional adaptations in the public interest. This is not a value-neutral endeavor, but should be geared toward positive support of the need to promote certain fundamental values at the heart of good governance (Organisation for Economic Co-operation and Development, 2001).

The need for activist leadership in contemporary governance is underlined by the increasing complexity in the public sector. Public-sector leaders as change agents, visionaries, and idea champions (Bahnareanu, 2012) must constantly adapt to political and environmental changes, while guiding followers to deliver higher performance in public service delivery.

Abah (2012) argued that a combination of an activist political and organizational leader is the key to unlocking public-sector-driven reform success. Abah's position appears to have received support from findings of earlier studies of atypical organizational performance in governance states or environments lacking the requisite state institutions for upholding the rule of law and other democratic structures of social accountability. Earlier research (Leonard, 2008) highlights several interrelationships among factors of organizational effectiveness and identified effective leadership as having a key role in the perceived atypical organizational performance in a developing economy context. 


\section{Summary}

This review of literature has focused on the importance of effective leadership with an emphasis on activist leadership as an atypical approach to public sector leadership in contemporary governance, especially in a developing economy context. These contexts are characterized by weak state institutions and corruption, resulting in poor service delivery to citizens (Abah, 2012; Agba, 2012; Gray \& McPherson, 2001; Leonard, 1987, 2008; Thomas, 2008; Thomson, 2004).

An important observation from the review is that despite a preponderance of leadership research focused on the nature and importance of leader-follower interactions, organizational effectiveness, as well as the contextual factors of environment and culture in relation to the effectiveness of leadership, a gap still exists in understanding the role of the individual activist leader, especially in nation states where institutions and agencies have weak governance structures.

A vast majority of examples of activist leaders studied in the literature have all been drawn from the developed economies of North America and Europe (Goethals, 2005; Greenstein, 1979; Organisation for Economic Co-operation and Development, 2001) and the emerging economies of East Asia and China (Li, Tan, Cai, Zhu, \& Wang, 2013).

This review suggests that the underlying leadership imperatives remain the same in similar democratic contexts, and new insights are required for research aimed at this breed of leaders in the developing economies in Africa. The aim is to promote a leadership development paradigm that public institutions can nurture as they aim to develop new leaders in developing countries (Abah, 2012; Afegbua \& Adejuwon, 2012; 
Goke, 2006). A structured approach of this nature undoubtedly contributes to a better understanding of public sector leadership.

A further justification for a more critical look at activist leadership is the need to understand the actual level of effectiveness of the approach in delivering on the objectives of leadership in the public sector. This is important due to the multi-factorial nature of measures of leadership effectiveness, so that leadership outcomes as a result of activist leadership can be understood in its context as a result of the application of this particular style, rather than mere serendipity.

The notion that effective leadership can sometimes be a result of sheer coincidence as reported in literature suggests that attributing leadership effectiveness to organizational performance requires more than a cursory approach to empirical research (Ancona et al., 2007; Dhar \& Mishra, 2001; Göran \& Wood, 2005). This realization makes it imperative for leadership research to focus more on understanding the nature of relationships that may exist between activist leadership and organizational effectiveness in the public sector. 


\section{CHAPTER 3}

\section{RESEARCH METHODOLOGY}

\section{Introduction}

Nigeria's young democracy has witnessed the emergence of a new breed of leaders faced with the challenges of delivering good governance outcomes within the weak institutional environments inherited from past military regimes characterized by a culture of corruption and lack of accountability. These leaders are changing the political and institutional landscape of the governance environments inherited from past military regimes, thereby strengthening the institutions they lead.

This study uses a qualitative research paradigm, as it is better suited to explaining and understanding complex, interdependent human phenomena than studies focusing on numbers (Miles \& Huberman, 1994). Qualitative research also emphasizes nuances, sequence, and multiple perspectives (Creswell, 2012) by using interviews, focus group discussions, observation, and document analysis as its main methods of inquiry. Furthermore, it gathers data for creating an interpretive storyline and allowing the emergence of substantive theory.

The goal of this research was to develop a grounded theory regarding how the leadership competencies/qualities exhibited by activist leaders in a young democracy support the achievement of above-the-norm organizational performance in the public 
sector, despite the constraints of weak governance institutions within their specified contexts.

\section{Research Question}

The research explored the following central question: How do these activist leaders exercise leadership in a different way than what is practiced in their governance context?

\section{Research Design}

The primary method of investigation adopted for this study is a grounded theory approach (Strauss \& Corbin, 1994, p. 273), a general methodology of qualitative research designed to build substantive theory based on the systematic collection and analysis of data. The grounded theory qualitative research design, as developed by Glaser and Strauss, was based on the assumptions that "social research were often inappropriate and ill-suited for participants under study without taking cognizance of the actions, interactions, and social processes of people" (Corbin \& Strauss, 2014; Glaser, 2004). Thus, grounded theory provides for the emergence of a theory "of actions, interactions, or processes through interrelating categories of information based on data collected from participants in their natural or field setting" (Creswell, 2012).

A grounded theory approach involves collecting data primarily through a series of open-ended interviews. These are then analyzed through comparison of incidences for common themes and categories towards highlighting emerging theory.

According to Strauss and Corbin (1998), as cited in (Creswell, 2012 Location 1845): 
This data analysis is initially through the use of open categories, first by selecting one category to be the focus of the theory, and then detailing additional categories (axial coding) to form a theoretical model. The intersection of the categories becomes the theory (called selective coding). This theory can be presented as a diagram, as propositions (or hypotheses), or as a discussion. Data analysis can also be less structured and based on developing a theory by piecing together implicit meanings about a category. (Charmaz, 2006)

This preferred approach generated a broad description of traits and/or behaviors of an activist leader from the participants' views of the phenomenon of activist leadership by articulating a storyline through ongoing refinements of the data from participants (Corbin \& Strauss, 2014). The resulting theory attempts to explain how the participants characterize activist leadership in the context within which it is being explored, and may also shed more light on how this phenomenon can be explored beyond the context of this study.

As a method for developing a substantive theory from qualitative data using a conditional matrix, this approach generated a conceptually dense theory (Strauss \& Corbin, 1994, p. 274) that is able to account for the many interrelationships between the leadership qualities/behavior of this crop of leaders and above-the-norm, public-sector performance in weak governance environments by "piecing together implicit meanings" about the different "categories of data, conditions, strategies, conditions and context, and consequences" (Charmaz, 2006, p. 10).

In adopting this social constructivist perspective that includes emphasizing “diverse local worlds, multiple realities, and the complexities of particular worlds, views, and actions". The emerging grounded theory was deduced from iterative comparisons of categories/themes based on "the experience within embedded, hidden networks, situations, and relationships" (Charmaz, 2006, p. 132). It also highlighted hierarchies of 
power, communication, and opportunity within which the phenomenon of activist leadership develops as "a central phenomenon, its causal conditions, strategies and contexts for which the consequences" are explored (Creswell, 2012).

\section{Interview Protocol}

An interview protocol was developed for the purpose of this research, and this included the project name, date, time, and place of the interview, as well as the interviewee's name and position. In addition, a brief description of the project was provided to participants, along with a set of open-ended questions to explore activist leadership. The proposed sub-questions included in this exploratory interview were to solicit answers from these leaders and their associates regarding (1) How they would describe an activist leader in a public sector leadership context, (2) insights into their memorable incidents about leadership, and (3) a description of the most distinguishing features of their leadership style that they believe are critical to their success. These were explored in detail in the attached protocol (Appendices A and B).

In following the traditions of the grounded theory approach, these questions were supported by other prompting questions to further highlight the participants' responses after the initial in-depth interview session. This approach follows the inductive nature of grounded theory research and the requirement of the researcher's responses as an active listener to improve the quality of the discussion and interpretation of generated concepts. These were later included in the report of findings.

An initial set of interviews on the purposive sample of participants was followed by the use of a theoretical sampling approach. This included a series of detailed, semistructured, open-ended interviews, supplemented by a study of documents, articles, 
and/or books on the subject of activist leadership. Adopting a theoretical sample for further interviews became necessary after the initial round of interviews was informed by the need to develop a conceptual theory from the themes generated by the first round of interviews conducted on the purposive sample. This approach also affords the opportunity to discover variations among the participants' interpretations of shared concepts in order to "densify" identified themes arising from previously collected data (Corbin \& Strauss, 2014, p. 15). The goal was to achieve theoretical saturation toward explicating and refining the emerging theory by following a deductive logic for further conceptual elaboration (Breckenridge \& Jones, 2009).

\section{Self as an Instrument}

As the investigator, in following the grounded theory's tradition for setting aside an investigator's bias as much as possible in order to discount a priori "theoretical ideas or notions so that the analytic, substantive theory can emerge" (Creswell, 2012; Glaser, 2004), I hereby provide my background and relationship with the study context as a means of highlighting my biases. This disclaimer, in a way, serves to maintain a distance between my preconceptions in relation to the study contexts and the participants' views and meanings, with the aim of presenting a disciplined focus on the objective of the study and reduce subjectivity (Heshusius, 1994).

I have been a keen observer of the phenomenon of activist leadership in publicsector organizations in Nigeria for over a decade, having worked in key sectors of public governance within international development agency frameworks. I held several resource management roles for multi-sector, bilateral development support projects in Nigeria aimed at reforming education, health, and social services delivery. These projects were 
targeted at improving governance outcomes for citizens, a cause to which I am very passionately committed.

My current advisory and executive coaching role is to provide technical assistance to the senior special assistant to the president on service delivery. This familiarity to the leaders studied has provided me with access to some of the key actors in Nigeria's political leadership class, and I am therefore exposed to some of the idiosyncrasies of this class of individuals referenced in my study. This makes it inevitable that there was an element of subjectivity, but I have made every effort required to minimize researcher bias, even though my subjective involvement with the proposed research has the potential to influence the project. The reason for this assertion lies in Glaser's (2004) rebuttal of Lincoln and Guba (1985) regarding grounded theory's lack of "immunity from facts". Grounded theory "does not generate an immune theory—immune to facts, which is, of course, a major problem of received theory" (Glaser, 2004). With this in mind, I believe my personal familiarity with and closeness to this research has the capacity to enrich the project, as I bring valuable meaning and understanding of the political economy of governance in Nigeria to the interpretive framework of the study.

\section{Purposive Sample}

Participants in this study were identified leaders who have delivered above-thenorm positive outcomes for the public-sector organizations they led. A purposeful sample of seven participants were interviewed, from which a number of propositions were generated from the data collected.

The following criteria were used in selection of participant leaders: 
a. Past/present public-sector leaders, identified by perceived improvement in organizational performance during their tenure in public office (as elected or appointed public officials) — either by initiating or supervising radical and systemic changes in their public-sector spheres. Such changes were associated with the achievement of between $30-50 \%$ of the organizational performance targets, in terms of verifiable indices of performance against organizational mandates or stated targets using commonly agreedupon empirical performance measures within the public service.

This selection criteria utilized evidence drawn from public documents and historic data from the National Bureau of Statistics to highlight performance improvements when compared to previous periods before the participants tenure of office.

b. Leadership activism as demonstrated in their use of public office to effect social change within their leadership context. This can be in the form of direct efforts to protect the weak in society, or just ensuring that governance benefits are delivered better in an innovative way that wasn't previously normal in their domain. The leaders' activism could also be in form of their commitment to transparency and the rule of law as key ingredients of good democratic governance.

c. Participants were also recruited based on the length of tenure in a publicsector leadership role. Elected officers are deemed to serve a four-year term by Nigeria's Electoral Act, while appointed public-sector leaders may serve for a period determined by their appointment. A three-year tenure in the public-sector leadership position was the minimum for consideration as a participating activist leader.

d. Representative balance among participants, in terms of levels of publicsector leadership. Participants were drawn from national and subnational levels. Gender 
considerations for both male and female leaders were explored, as well as the geopolitical spread across the country's six zones. This was an attempt to draw a representative pool from the over 250 ethnic groups and subcultures in Nigeria, as well as deepen the insights about the influence of these subcultures on leadership development in a multiethnic, developing, country context.

e. Proposed participants were also subjected to an expert review by the identified expert of the subject matter, Dr. Joe Abah, the Director General of Nigeria's Bureau of Public Service Reforms. A distinguished governance expert whose agency is vested with a mandate "to initiate, coordinate and ensure full implementation of government reform policies and programmes". He has a wealth of experience in the governance context and an intimate knowledge of the challenges of Nigeria's public sector and leadership constraints.

These five selection criteria were applied in the following order, with a view of a broader representation considering the variation in the types of public sector organizations in the Nigerian context.

Once a full list of individuals who meet the five criteria was collated, an initial set of four participants was identified and selected from the pool of activist leaders using their length of tenure (criterion c) as the secondary criteria. This draws support from public sector leadership literature regarding tenure stability as a predictor of leadership effectiveness in public sector settings (Kaatz, 1996), and the assumption that having spent much longer in public office, these leaders can provide richer insights for exploring their leadership effectiveness. 
It was envisaged that this study can generate different perspectives of character traits, behaviors, values, or dispositions of activist leaders through this broad variety of parameters.

\section{Data Collection}

This research focused primarily on qualitative data gathered from interviews with the participants, researcher's observations, focus group discussions with their associates and subordinates, review of relevant documents/artifacts and records of these leaders at work, and a research journal chronicling the ongoing reflections during the entire data collection process.

\section{Participant Interviews}

The one-on-one interviews were largely conversational and provided opportunity for introspection and reflection by participants. This was achieved by making questions from the interview protocol available in advance before the audiotaped interview sessions were conducted at sites of the participant's choice—often their office or homes, depending on personal preferences. Interviews were conducted with seven identified activist leaders and transcribed before initial coding for themes using Nvivo 11 software.

This phase was an iterative process of "constantly comparing data gleaned from participants with ideas about the emerging theory". Coding for themes began from the very first interview and the process continued with "going back and forth between the participants, gathering new interviews, and then returning to the evolving theory to fill in the gaps and to elaborate on how it works" (Creswell, 2012). The interview guide and protocol are attached in Appendix A. 


\section{Observations}

Participants were observed in their natural setting. This involved "noting a phenomenon in the field setting through the five senses of the observer, often with an instrument, and recording it for scientific purposes" (Angrosino, 2007, as cited in Creswell (2012). These observations were intended to reflect insights based on the research questions and provide a rich resource for interpreting the participants' contributions in order to "address issues such as the potential deception of the people being interviewed, impression management, and potential marginalization of researcher in a strange setting" (Creswell, 2012). In addition to a record of observations of these leaders' work environment, nuances of behavior and temperament, including verbal and nonverbal cues, were also recorded.

An observation protocol for recording relevant information on site-setting, participant interactions and reactions, interviewer hunches, and initial interpretations with regards to the interview site is attached in Appendix A.

\section{Key Informant Interviews}

Interviews with a representative/mixed sample comprising four associates, colleagues, and subordinates of five of the interviewed participants were conducted with the aim of providing validation for the emergent themes in the participants' stories. This also served as a form of triangulation, because it helps to "corroborate evidence from different sources to shed light on a theme or perspective" (Creswell, 2012). The key informant interviews were recorded using an interview and recording protocol that mirrors the research protocol, but coded to reflect the emergent themes from the participants' data. The key informant interview protocol is attached in Appendix B. 


\section{Review of Relevant Documents and Artifacts}

Evidence from the participant interview data also incorporated an extensive review of available public documents. There were also significant efforts at articulating a public persona of these leaders from curated content from public and private documents, autobiographies, Internet webpages, archived newspaper articles, and other self-generated content revealing insights into the participants' leadership style.

\section{Research Journal}

Field notes and journals recorded from these interactions throughout the datagathering and analysis phases of the project were stored and used as memos to aid the process of activist leadership theory formulation. The journal provided a place to capture "reflective notes" about the data collection process (Creswell, 2012). It was also the repository for initial reflections on activities and summary conclusions about ongoing research and data collection for later theme development.

\section{Data Analysis}

Data based on transcriptions of semi-structured, in-depth interviews and documentary evidence were analyzed for "concepts and context to identify patterns" (Glaser, 2004) and the development of a conceptual framework of activist leadership associated with atypical performance in weak governance public-sector environments/states. This process began immediately with the first interview and involved the coding and conceptual abstraction of data in the traditions of classic grounded theory research by using both substantive and theoretical coding techniques (Holton, Bryant, \& Charmaz, 2007). In the latter stages of the coding process, codes were elicited through a "joint process of theoretical sampling and memo-writing" so that 
emerging codes were "corrected, trimmed, and continually fitted to the data" (Breckenridge \& Jones, 2009, p. 115).

Substantive coding —-"the process of conceptualizing the empirical substance of the area under study" (Holton et al., 2007)—utilized line-by-line coding (open coding) of responses and an iterative comparison of incidences in order to identify categories and pattern recognition beginning from the first interview. Conceptual "memoing" using records from the researcher's observations, reflections, and initial conceptualizations aided the conceptualization of boundaries and properties of each category, and these became useful tools for "illuminating gaps in the emerging theory, thus highlighting where to sample next and for what theoretical purpose" (Glaser, 1978, as cited in Breckenridge \& Jones, 2009 p. 115).

By using further comparisons in three distinct levels of (i) incidents to incidents, (ii) incidents to categories/concepts, and later (iii) concepts with concepts, the data yielded core categories from which further theoretical samples were generated for theory building (Holton et al., 2007). This theoretical coding process comprised several iterative processes in order to produce a conceptually dense theory, one defined in terms of the plausible relationships proposed among concepts or sets of concepts (Strauss \& Corbin, 1994, p. 274). The resulting data was analyzed by comparing and sorting the researcher's field notes and memos, selective coding for intense property development among core categories, writing theoretical analysis memos, and comparing emergent relationships. Axial coding techniques were used for the purpose of determining possible causal conditions, context, intervening conditions, strategies, and consequences to the central phenomena. Corbin and Strauss defined axial coding as "crosscutting or relating concepts 
to each other" as cited in (Schwalb, 2011, p. 39). These steps were followed by developing a series of visual models from the emerging relationships resulting from additional selective coding.

\section{Validity Issues}

The qualitative research approach to validation can best be described as "an attempt to assess the accuracy of the findings, as best described by the researcher and the participants" (Creswell, 2012). This view of validation as a distinct strength of qualitative research is achieved using processes that require extensive time with participants in the field, detailed thick description, and the closeness of the researcher to participants in the study aimed at adding value and accuracy to the study. In order to further strengthen the quality of the evidence gathered and evaluated in this research, a five-stage approach was utilized.

The first validation strategy was triangulation, which was executed by using multiple sources of information to corroborate evidence and emerging themes (Lincoln \& Guba, 1985). Data from the interviews were checked against available records/evidence in the public domain regarding incidents and circumstances related to the participants.

A second step of peer review was conducted by identifying a peer-debriefer as an external check of the process. This role is a type of "devil's advocate", an "individual who keeps the researcher honest; asks hard questions about methods, meanings, and interpretations; and provided the researcher with the opportunity for catharsis by sympathetically listening to the researcher's feelings" (Creswell, 2012; Lincoln \& Guba, 1985). 
The third step in the process was the key informant interviews with associates of participants to corroborate the researcher's interpretation of data from the participant interviews, thus avoiding the pitfalls of a "single lens" paradigm in a qualitative inquiry, such as was used in this context (Creswell \& Miller, 2000). This approach also moderated the researcher's role as an active listener and collaborator who expresses not only the view through the researcher's lens, but also strengthens results through the active involvement of participants in filtering their individual views.

The fourth step was a member check. In line with qualitative traditions, the outcome of the coding exercises was referred back to the participants to ensure accuracy and credibility of the critical observations, findings, and interpretations (Creswell, 2012; Lincoln \& Guba, 1985). A final step included an external auditor's review of a sample of the interview transcripts for comparison with the researcher's coding.

The processes outlined above served to strengthen the accuracy of the findings using the five strategies deployed in this study, and this was supported further by extensive time spent in the field in order to make decisions about "what is salient to study, relevant to the purpose of the study, and of interest for focus" (Fetterman, 2010).

\section{Generalizability}

Qualitative research's traditional view of generalizability of findings is based on the degree to which the study finds a "fit" in its application to the issue investigated in the readers' context. This invariably places the onus on "the readers, rather than the investigator" (Creswell, 2012; Eisner, 1991; Erlandson, Harris, Skipper, \& Allen, 1993; Lincoln \& Guba, 1985) for determining connections between the study's findings and particular context of review. 
In seeking a better understanding of personal leadership in the public sector, the research presents important considerations for current and future public sector leadership development in young democracies particularly, but it also has wider applicability across contexts. This research provides a kind of "transferability" that allows readers to gain invaluable insights into how activist leaders lead public sector organizations to achieve above-the-norm performance when institutional frameworks are weak and positive governance outcomes are needed.

\section{Ethical Issues}

This study of adult human subjects required approval from the Andrews University Internal Review Board. The approval was sought prior to commencement of the project, and this was communicated to prospective interviewees. Participants were informed of my intention to report on the findings of this study in a doctoral dissertation and the possibility that I will submit this work for publication.

Interviewees were assigned codes to provide a certain measure of confidentiality in the reporting and publication process. Confidentiality was also supported through the use of pseudonyms and careful attention to descriptors. Interviewees were invited to comment on and approve the confidentiality level of the report prior to its submission. They were also informed that, as the investigator, and for purposes of this research, their approval of the interpretation of events or the content of the report will not be required.

Interviewees were provided with a protocol that describes the background to the problem, the problem, the purpose of the study, my research question, and an overview of the research methodology. Written consent forms were duly signed by interviewees before participating in the research. 


\section{Summary}

This research explored the question, "How do these activist leaders exercise leadership in a different way than what is practiced in their governance context?". It consisted of a qualitative research study drawing on the grounded-theory tradition to generate a theory of activist leadership in a young democracy. The primary methods of data collection was through interviews with participants, researcher's observations, key informant interviews with their associates/subordinates, review of relevant documents/artifacts and records of these leaders at work, and a research journal chronicling the ongoing reflections during the entire data collection process.

Analyzing the data in the traditions of classic grounded theory included open coding and axial coding towards building a conceptually dense theory of activist leadership. Data validation was conducted using well-known tools for measuring success in qualitative research - triangulation by drawing from multiple sources of information; peer-debriefing by asking the debriefer to review and give feedback; a member-check to seek the participants' review and acknowledgement of data; and an expert audit to check theoretical sensitivity.

There was full disclosure of the process to the interviewees by means of written consent forms as an ethical research effort. These steps supported the development of a grounded theory that describes how activist leaders achieve above-the-norm performance in the organizations they lead. The applicability of the theory is based on its useful fit for leaders in other young democracies and transitioning economies seeking improved governance outcomes in weak institutional environments. 


\section{CHAPTER 4}

\section{THE RESULTS}

\section{Introduction}

This chapter presents the research results by highlighting the participant profiles, interview responses, results of data collection, coding, and analysis. The purpose of the grounded theory study was to investigate the phenomenon of a small but growing group of Nigeria's activist political leaders, who are redefining public sector governance by reshaping the organizations they led, thereby improving the institutional environments of hitherto ineffective public agencies.

\section{Research Participants}

A purposeful sample of seven participants were interviewed for this research. These were public sector leaders who satisfied the five selection criteria for participation in the research. They were individuals who have held either an elective or appointed public leadership role and can be identified with perceived improvement in organizational performance during their tenure in public office — either by initiating or supervising radical and systemic changes in their public-sector spheres. They demonstrated leadership activism in their use of public office to effect social change within their leadership context. The leader-participants were in public office for between three and six years tenure, and were drawn from a representative sample across the three levels of governance. Their selection was validated through an expert review. 


\section{Participant Profiles}

Aminu is a 48-year-old male public-sector leader who held appointed positions at the state and federal level for a total of seven years. In his roles, he has initiated sectorwide reforms in education and youth development. He was recognized as an effective leader who secured significant changes in both sectors-first at the subnational (state), and subsequently at the national level as a federal minister. He is a native of one of the states in the North central political zone.

Binta is a 56-year-old female leader who has held three different roles at the national level for a period over eight years. She was initially appointed into a Presidential advisory role, and later became a federal minister responsible for two different ministerial portfolios. She managed a conditional grant transfer scheme which delivered basic services to the poor and vulnerable across the country - a scheme highly regarded as one of the most transparently administered in the world. She is from one of the states in the North central political zone.

Amaka is a 54-year-old female leader who also held three different roles at the national level of governance. She held ministerial roles in two different portfolios at the national level and was a leading pioneer for a series of institutional reforms in ensuring transparency and accountability in governance. She is a native of one of the states in the Southeast of the country.

Nnenna is a 55-year-old female leader who held an appointed position as the head of a national institution for a period of eight years. Her role saw the complete turnaround of the hitherto moribund organization and repositioned it as a key contributor to national development. Her accomplishments at the organization was so unprecedented that she 
was acknowledged by the World Economic Forum in Davos as a global leader of tomorrow. She is a native of the South-south political zone of the country.

Ade is a 54-year-old male leader. He was initially appointed into a public-sector role at the subnational level, and later secured an executive elective position at the subnational level before serving as a minister at the national level. He has been in public leadership roles for over 12 years - four years in an appointed role and eight years as an elected political office holder. His tenure as executive state governor remains a benchmark in leadership attainment at the subnational level of government. He is from the Southwest zone of the country.

Turaki is a 56-year-old male public-sector leader. He was appointed into the leadership role at the national level where he led a national organization responsible for law enforcement and tackling endemic corruption in the country. His pioneering role in the agency and positioning it as a credible institution has been cited in literature as an example of best practice in global anticorruption reforms. He is from the Northeast of the country.

Onyekachi is a 52-year-old male politician/public sector leader. Initially appointed in a subnational leadership role, he was later appointed twice as a federal minister and had a public leadership role for six years. His reform of the two ministerial portfolios he held has led to significant improvements in citizen access to government and public information and service. He is from the Southeast of the country.

\section{Key Informant Profiles}

In addition to the participants, four key informants were interviewed to provide support and evidence to the claims of the participants. These were associates of the 
leaders interviewed in the research. They were individuals who had worked closely with the identified leaders and experienced their exercise of leadership — either in the public or private domain.

Damola was an associate of two of the named leaders in this research—Nnenna and Ade. He had worked closely with them at different times in his career. He was a subordinate of Nnenna while she headed a consulting firm and also supported Ade as a consultant working on a public accountability project. He is an experienced development professional with over 15 years of experience in development programming for public sector reform. He is from the Southwest of the country

Oghene is an associate of Binta. He served with her in the Civil Society movement, and they have remained close professional colleagues for over 15 years. $\mathrm{He}$ supported her in her ministerial role on a pro-bono basis for a period of one year. Oghene is a respected civil society advocate and scholar. He is from the South-south region of the country.

Amanda was an associate of Aminu. She was a member of his reform team while he was a minister in the federal cabinet. She worked directly with him in managing the reform process that resulted in the restructuring of the National Football (soccer) League. She is from the Southeast of the country.

Adakole was an associate of Turaki. They have a longstanding relationship that dates back to Turaki's days as a senior law enforcement officer in one of the southern states. Adakole's experience with Turaki's leadership has been for over 15 years. He is a native of one of the states in the Northcentral region. 


\section{Findings}

The research explored the unique dispositions, skills, values, and/or behaviors of this class of leaders in order to provide an understanding of their emergence in terms of their development, decision making, and other personal leadership characteristics that evolved into their "activist" nature. The study was designed to explore the following central question: How do these activist leaders exercise leadership in a different way than what is practiced in their governance context?

Three major themes emerged from my interviews with the public-sector leaders. These include (a) their managerial and personal leadership approach; (b) their cognitive approach towards achieving governance outcomes; and (c) their pragmatic leadership approach to resolving leadership challenges of weak institutional contexts.

\section{Leaders' Managerial and Personal Leadership Approach}

The leaders reported many instances where their competence, integrity, and capacity for effective leadership was required in delivering effective governance outcomes. Even though they had evolved through different professional pathways, there was a common thread in their public-sector career trajectories irrespective of gender. They were all university-educated graduates and had spent an average of 10-15 years in professional/leadership positions in private sector organizations before being "recruited" into the public-sector roles they held.

\section{Competence}

The interviewed leaders had developed into competent individuals by developing skillsets for effectiveness in leadership. They reported instances where their leadership 
roles in the public sector required drawing on knowledge and skills which had been acquired in the process of career development outside the public domain. There was considerable dependence on previous training and experience in using a combination of skillsets from their education in specific professions.

The participants were established professionals in law, journalism, health-related disciplines, financial services, economics, etc. They brought to their roles a fullydeveloped set of skills from ordered work environments, mostly in the private sector. Their competence was expressed in their reference to having a sense of vision, strategic thinking, and ability to follow through on a course of action, even when no clear direction was articulated by their public sector principal (either the President or State Governor, as the case may be). This ability to conceptualize solution pathways required of them a combination of a decent education and good quality experience.

This view was evident in Aminu's assertion that in addition to good training, good experience matters. Competence was described in terms of having the right training, combined with the right experiences, as an important element of effective leadership in this context. He quipped further that even though "there were lots of very educated people, probably with good value systems in their homes, but without the experience and exposure they were not able to take on the challenge-Nigeria".

Binta was making the same point about competence and how it was pivotal to her success in contrast to other public sector leaders in the previous federal cabinet, and how the lack of competence might hamper leadership effectiveness. She went further to state that competence involves having the "right skills". From her experience in leadership, "somebody must be skilled; they must be trained and must have the cognitive capability 
to be able to connect the dots". She described competence more in terms of the leaders' ability to exercise the "intellectual capacity for analyzing problems". In her view, her competence was demonstrated in being able to "intellectually process what exactly the problem really is, and to have that mind of enquiry that will enable me look at options and mobilize different resources that would solve a problem".

Amaka made a similar comment in attributing her competence to the classification of persons considered to be effective leaders because they were not from the "traditional" political class or "career politicians". They were called "technocrats" and acknowledged as a different breed of public sector leaders who are knowledgeable enough to deliver results in the public arena. The term "technocrat" was coined in the Nigerian public leadership lexicon in the 1980s when the military government in power began appointing well-educated civilians, mostly from academia (with no known political background or experience) into the military-led government. These followed a period when previously elected politicians were banned from public offices as part of the anticorruption crusade of the era.

Amaka made the point that as a technocrat, her effectiveness could be attributed to her being an accomplished professional. Largely because technocrats were perceived as brilliant people who are immune to the undesirable effects of political decision making and sometimes put politics before sound judgement. In her view, being competent meant being "effective in public leadership using her knowledge and skill” to achieve results.

In a sense, it appears to be that participants reckon that being competent in leadership requires the leader to be "someone who is knowledgeable at least" and able to use his/her knowledge and experience in a way that makes them effective at tackling 
public-sector leadership challenges in their context. Onyekachi expressed it this way: "When I say knowledgeable, you don't have to be an expert but at least have some decent education". He believed in being the beneficiary of a decent education and gained experience using that education at a leadership level. In his view, "If you aspire to leadership, you must prepare yourself". He mentioned how he declined new appointment opportunities "because [he] wanted to go back to school to prepare for the future". In a bid to become more knowledgeable, he also believed leaders must be "someone who is open-minded".

Open-mindedness for Onyekachi is to value knowledge. "I value superior arguments; I'm someone who...I bow to superior knowledge". This has enabled him to work with a pool of some of the smartest teams. In his words, "Part of what helped me was that I had a team of very smart people, people from diverse backgrounds, from different parts of the country". He was able to build these diverse teams for tackling some of the tough challenges he faced while in public office.

Nnenna shared a similar view in being open and able to identify expertise when she said, "Today I'm in a ministry where I don't have any professional background", but because she has "lots of experience on how to deliver on an issue", she constantly "looks for expertise around [her] and then bring it together by looking to deliver first". She has been able to get "a very clear road to plot what can be done" with challenges in her public leadership by being open to and able to evaluate expert advice.

\section{Integrity}

Subscribing to a set of moral qualities, ethical standards, and principles appears to be a common thread in the personal attributes to which these leaders ascribe. They were 
firm believers in maintaining a good moral compass and holding themselves to a higher moral standard, based on their personal convictions and moral values.

Binta believed she wouldn't have survived in office, or attained her current public leadership appointment, if she had no integrity. She opined that "if you've got proven integrity, then you're good for it”. Proven integrity, in her view, has no other criterion other than a moral virtue one has that can be "experienced and can be vouched for". She went on to assert that her first appointment into public office was because the former President Obasanjo could trust her. She was convinced that her high moral standards in the face of endemic corruption in public service was crucial for success in her leadership role, and this explains why she had been tasked with managing a conditional cash transfer scheme worth $\$ 500$ million.

Binta further stressed the role of her upbringing in developing integrity in leadership. She stated that "It's my upbringing, it's my training, it's my experience, it's those three things". For her, those three are what make a leader. When probed about her upbringing, she related to it in terms of having "a set of values that you will not compromise as you grow up". In her words, these are embodied in the "roots and wings to fly". The "roots are your values, your culture, your religion and the wings are the education". For her, the moral values from early life socialization experiences are the roots that sustain consistent moral action in later life, and especially in the public leadership domain. She concluded by saying, "What you stand for in your home does influence what you do in the public place".

Oghene further added that in his experience with Binta, it was obvious that on any issue, she was clear about what she wanted to achieve and that her decisions were "not 
colored by material considerations". This, in his view, enabled her to attract the best kind of people. He was also affirming her integrity in an environment where other primordial considerations cloud decision making. He was quick to add that even though she is Fulani (from the North), her core team was made up of people like him - an Urhobo (from the Niger Delta). This, in his view, meant she was above the primordial sentiments that corrupts effectiveness in the public sector.

There was also the case of Amaka, who was involved in driving a radical reform in two federal agencies where she led for over four years. As far as she was concerned, "Character is fundamental and foundational". She believed her character, which was developed through her upbringing instilling a moral value system which helped her to make a difference in public life and ultimately defined the type of leader she became later in adulthood. According to her paradigm, she went further to describe leadership without character as a locust, which ends up destroying the very fabric of society.

She made specific reference to her effective leadership as being able to "combine integrity, the ethical standards" with good career experiences. She perceives moral character in terms of "ethical standards of behavior" as developed by her family socialization, and believes this is the bedrock from which effective leadership grows in relation to education and experience. In her estimation, "Knowledge is as important as the integrity factor of leadership... without the knowledge, the integrity factor was insufficient".

Onyekachi further linked his moral anchors to how they defined his purpose as a leader and a way of life that he adopted. He pointed out his "courage of conviction in the values that shaped him". He also pointed out that "a life of purpose drives" him and that 
leadership is about service. Seeking "to meet the needs of those around him were more important that being obsessed with what the gains of the office affords". To Onyekachi, this is "a function of understanding how much of privilege" you have as a leader. He further affirmed this view with his comments on the importance of integrity in leadership: "I'm prepared to negotiate my views, but I'm not prepared to negotiate my values".

The interviewed leaders seem to have very strong personal convictions about how they perceive the role of a good moral character and integrity in their leadership. They believed that integrity was a key factor for success as evidenced by comments by Amaka and Nnenna.

Ade further remarked that in ensuring that integrity prevails, a leader needs not only be aboveboard; he must avoid anything that is inconsistent with his moral stance. He made the point quite elaborately with this anecdotal statement: "You cannot combine personal gain with the desire to make change", otherwise "you will be humiliated". This is because 'you have to 'kick ass' at some point and you can't 'kick ass' if you share money, or if you are part of it (corruption/embezzlement)". His anecdote was a classical one in Nigeria's public service parlance, that "if your directors share money with you today, you can't come tomorrow to say you are suspending him/her for incompetence/lack of performance or else he will ask you - are you mad?"'

Participant leaders were clear about their reliance on personal values in developing and using integrity in their leadership. Aminu made his point thus: "In talking about values, the values that I hold dear today, values of honesty, values of hard work, courage, fortitude, integrity, loyalty, commitment, patriotism are values I learnt from my father". He further claimed that these values form his "first principles" and he has taken 
personal responsibility for developing them into his canon of leadership to the extent that "I'm very intemperate and very intolerant of sloppiness of any kind, or malfeasance. I have absolutely no accommodation for it and people who tried to lure, to seduce, to negotiate things".

These comments are instructive in understanding the leaders' self-awareness about the implications for effectiveness in their context, as well as the key role of integrity in their leadership. The central question that underlies moral and ethical decisions for most of the participants was: Have you taken this course of action to your personal advantage? This is because, according to Aminu, "You cannot work in the public sector and carry out successful reforms without making compromises".

Integrity for these leaders also included fairness and justice in decision making. This is especially important in a multiethnic and multi-religious country where public officers wield enormous powers to dispense favors and gratify close associates. Binta put it this way: "What I have to do is to ensure that I'm fair". Even as she considers her allocation decisions, "I have to think about religion, it's not to think that it is my religion that will prevail, it's to think that okay if they need this to have a religious balance then I have to look at it". She further said that she often looks "at the justice in her decisions". In her leadership roles, she has sought for "everyone to benefit, but I (her Fulani kith \& kin) shouldn't be left behind". In her view, this has helped her to ensure that she is always "looking at where the needs are", and this also entails that she has to have a balance.

Turaki had one of the most dramatic experiences in his leadership role. He recounted instances when he had to rely on his moral compass and reject huge bribes at the risk of his life and that of family members. He talked about integrity as taking a long 
hard look at the big picture of the impact of corruption in the lives of ordinary citizens. This moral compass helped him to "steady the ship" in a "morally deficient public arena" where corrupt officials will offer bribes, and he knew these very powerful men and women could "resort to any means necessary", including intimidation and threats to his life.

This moral compass was hinged on his firm belief in justice. Justice, according to Turaki, is blind. He will serve justice to both Nigeria's big men and small men in equal measure--"once you cross the line". His main mantra is to deal in fairness with everyone and with the "fear of God".

\section{Resilient Capacity}

The capacity to undertake the tasks needed for achieving set objectives is a key attribute that resonated with the group of leaders interviewed. There was a general belief that competence and integrity alone weren't enough to ensure effectiveness within the public leadership domain. The interviewed leaders were emphatic that being "capable of grinding out desired outcomes in the face of sometimes stiff opposition" was essential to their success.

Amaka affirmatively stated, "Capability is not the same thing as competence. You can be competent and lack capacity". In her view, being able "to take on the most daunting of tasks" reflects a capacity for leadership in the public domain. In one of her previous roles in public service, she needed to find a solution to the "very blatant problem of pillaging of the public treasury through scams and schemes of dubious contracts". She recalled studying the problem and "designing a system that could modify behavior" such 
that people were "no longer obeying the rules in the breach" and personally "working with other Cabinet ministers to ensure its acceptance at Federal Executive Council”.

Onyekachi, in sharing his view of capacity in public leadership, declared that "you need to have a solid individual, who will be able to weather the storm". In his view, capacity is what gives "such resilience that no amount of problem will prevent you from finding options that represent solutions". Being able to find options that represent solutions and the strength of character in implementing solutions constitutes the capacity element. This view was also buttressed by Damola (in his description of Nnenna) on the point by Onyekachi with a comment that "she oftentimes presented an articulate and intelligent argument to situations presented before her for decision making"; she always had "a knack for outlining pathways" to a solution and "walking the talk".

In the opinion of Nnenna, effective leadership needs a "cognitive capability to be able to connect the dots". To have capacity for public leadership is to have "the mind to be able to mobilize the different resources that would solve a problem". She believed her success also involves recognizing that "our problems are complex, so if you are competent and have low capacity for taking this to a logical end, the complexity of it will just overwhelm the person". The complexity to which she refers includes having to challenge entrenched interests in the implementation of viable solutions to public leadership challenges in a multiethnic and multi-religious society like Nigeria.

In placing a premium on capacity, associates of participant leaders pointed to their use of their leadership capacity, not just in themselves, but also in influencing colleagues. For instance, Adakole stated this regarding Turaki: "He values initiative, and people who have initiative. He values people who work with minimum supervision". Once he agrees 
to a vision, he expects that "whatever we need to do to get there let's get on with it. That's his kind of person". He believes in "contemplating the problems" with his teams, whether it is in the private sector or the public sector, and advances solutions without "time for any kind of mucking about".

For Aminu, capacity entails a "willingness to negotiate" solutions and approaches in a way that secures delivery of stated objectives. He stated that "I would be clear where I want to go, but I would also be able to tell myself that if I get half of the way...that is some success". He further noted that "once you say reform, people become defensive" because people are more afraid of what they stand to lose, when there is change, than what they stand to benefit. His approach towards gathering required support for a course of action, was to "identify those who will lose in a reform" and begin to engage them to give up what they currently enjoy for the benefit of change.

Capacity, in the view of Binta, is "recognizing the dynamics of political turnover" and its implications on embedding reforms in the public sector. In her opinion, being able to overcome the challenges of "short-termism" in outlook of a political administration and using the limited time in office to quickly "institutionalize reform" in a young democracy is critical to leadership effectiveness. For instance, she recalled her experience by sharing the fact that leaders have to be able to "deliver in a short time because that is all you have, and at the same time, you have to root things [so] that they will live after you".

This was in specific reference to the high rate of political turnover in Nigeria's emerging democratic process. She specifically mentioned that "every four or five years and every time we change, the turnover in two of the arms of government is up to $80 \%$ in 
the legislature and in the executive". This scenario makes it difficult to "manage institutional memory" for effective leadership and therefore challenges public sector leaders to "develop effective coping strategies" to deliver results.

The foregoing suggests that the leaders and key informants interviewed believe that these three elements — competence, integrity, and a resilient capacity — were pivotal elements in their achievement of leadership effectiveness in the context within which they operated. This notion appears to be an overarching theme and was acknowledged by all participants in various forms.

\section{Leaders' Cognitive Approach Towards Achieving Governance Outcomes}

Leaders have an innate desire to make a difference even when there are no set performance targets for them in the public leadership roles they had. It was instructive to note that only two leaders confirmed having a defined agenda on assumption of office, which was handed to them by their boss (the president, in the case of a federal minister and the state governor, in the case of a former commissioner). The remaining five leaders interviewed — some of whom held ministerial appointments in the federal cabinetconfirmed that they had no defined targets for their ministries, but had to set personal goals on what their performance target would be while holding public office.

\section{Intrinsic Motivation}

The lack of any clear performance targets for these leaders meant they had to find motivation from within themselves, for the modest achievements for which their tenure was noted. They had to draw on an internal drive which, for the most part, made these leaders more reflective and realistic in approach. It also meant they had to find ways of 
constantly defending their reform initiatives in the face of entrenched political interests which threatened these changes.

Ade was quite elaborate by recounting the fact that "there is no performance management in public leadership, and so what happens is, you create the reform initiative and try to market it to the person who hired you". He was describing the fact that chief executives — the state governor (in earlier positions he held) — did not have explicit performance targets assigned that could have helped in shaping the direction of reformminded appointees. His desire to make changes to the status quo in the ministry was therefore his personal initiative and was susceptible to forces within a government that has the capacity to conspire against him and make their efforts fail.

Aminu expressed this personal motivation to effect change as one being driven by his being "transcendental in your definition of what matters". By this he meant the need to be different from the "old breed" or the "typical Nigerian politician" who is seen as often not interested in doing the hard work of tackling issues of reform. He further stated that this nature challenges him to seek opportunities to make changes happen in the ministry under his watch. He therefore could not imagine himself not responding to governance challenges in his domain. He always asks himself the question- "How can this one behave like this?"-when he finds his colleagues in the cabinet not tackling obvious developmental challenges in their domains by placing "politics above the needs of the people".

For Binta, this personal motivation was borne from "an inner conviction to do good in her life and to make a difference in people's lives”. She maintained that she "never intended public office". However, since public office found her, she has "focused 
her inner strength" on this most important life mission. In her view, there might be a psychology type that is able to thrive on the desire to seek challenges where none present themselves in explicit terms. She further stated that in one of her previous roles, she literarily found herself trying "to look for ways to turn everything towards what matters; for everyone to get their needs and not their wants".

Onyekachi made the same point by saying, "It's about personal responsibility”. He puts this succinctly when he said:

I believe very strongly that leadership is about personal responsibility and the issue of responsibility is not something that happens in one day. It comes from nurture. It comes from a deep understanding of spiritual things, the implication of your actions.

He made this point to illustrate the differences in personalities of leaders and how he couldn't imagine some of his colleagues while in office could "divert large sums of money to personal uses"-monies meant for poverty alleviation for the most vulnerable in society. He couldn't understand the mindset of such people and it was clear to him that he was probably equipped with a different mindset, compared to most other people in the Cabinet.

\section{Achievement Focus}

A closely-linked attribute of these leaders is a high level of achievement focus on the tasks at hand. All the leaders interviewed provided recollections of a passion for achieving results in their various fields. They expressed a focus on creating value in the discharge of their functions in office despite the fact that there was "little or no real expectation" either from the public or their political principals who were either elected through the ballot or through an appointment to public office. 
Binta aptly described this scenario when she acknowledged that even her principal who had hired her to do the job did not have any template. There was no goal toward which to aspire in terms of development outcomes. Therefore, whatever she had achieved was based on her desire to get things done. This meant that she went out of her comfort zone on many occasions, just to improve on the status quo. Binta expressed during the interview that it took a kind of psychology type to initiate change in the public sector domain when the system is not set up to receive any disruptions.

In Onyekachi's opinion, this desire to achieve positive outcomes in public leadership was clear when he acknowledged that he "was never in doubt about his desire to get things done". This desire was fueled by his inability to settle for "just going to the office and review files". For him, the overriding factor was that he hates finding himself in a place where he does not have a problem to solve. He described sometimes finding out his goals and targets after jumping into a problem. He then starts to ask, "How do I get out of it?". It is in the process of "getting out of it" that he achieves the goals he has inadvertently crafted for himself.

Ade approached public sector leadership with "a simple philosophy of creating value". In "every situation where we have problems, there will always be solutions". There was always a need to get this thing done, and for him that was his own reward. This personal motivation to get things done, no matter the obstacles along the way, made it unacceptable to him that there could be an "army of unemployed youth" in his state who have defied every attempt to rid the city of their menace.

Amaka commented about her personal commitment to getting the job done when she said, "I pursued just getting the job done wherever I found myself and as long as it 
made a difference in people's lives". In a short period, she developed a reputation for delivering on the assignment-whatever it was that she was assigned. In affirming her achievement across multiple agencies, she was recruited by the World Bank to oversee several projects across sub-Saharan Africa at the end of her role in government.

Aminu was relaying his achievement focus when he related this to the fact that in his public-sector appointments, "There were no clear set performance objectives/targets in his appointment letter". He had to think of a way of using his understanding of the ministry under his care to define his performance management objectives. These objectives were then negotiated with his boss. He shared his personal dilemma when he had the privilege of working with former President Obasanjo, who he claimed is one of the few leaders of Nigeria having a very clear vision of what he wanted to achieve in office. According to him:

President Obasanjo interviewed each and every one of us, and, in some cases, he even wrote letters to some ministers telling them, applying what his vision was for those ministries, [then he would], from time to time, benchmark progress based on that letter he had sent you. However, despite these instructions, he was still left with the arduous task of isolating the right reforms to pursue among the myriads of options available in order to achieve results.

Nnenna also shared the same view of the role of her personal convictions in seeking to achieve good governance outcomes despite not being mandated by her context. In her words, "If I believe in a thing, I have courage of conviction around it and I'm going to do everything that is noble in order to achieve a result". Her courage of conviction led her to institute a legal challenge against the decision of the government 
with regards to transparency in federal revenue management frameworks. She challenged the government that appointed her and won. The legal victory was instrumental to her achieving significant independence for the regulatory agency, and this led to higher effectiveness in revenue management. She believed it was a risky move that might have costed her the appointment and was definitely not part of the plan of her principal.

Damola (an associate of Nnenna) appears to be corroborating this assertion of hers when he acknowledged that whenever the team was afraid or in a dilemma about certain decisions, she was always willing to "take the gauntlet and have the boldness and the courage on issues". He also noted the fact that, in most cases, she "had a kind of direction where she wanted to go" and was able to communicate that direction to her people. In his perception of Nnenna, this was an important characteristic that a leader needed — to be bold and set high bars for what was possible.

In the case of Amaka, she was clear about her intentions in public office long before her appointment. She was "taken in by what the people around her needed". It is this need that drives her to seek to serve. She sees her role in government as a privilege, and this propels her to pursue the ideas and goals of leaving her office with an achievement that alleviates suffering and "improves the public benefit of her service". She further made the point that her public sector role in setting up the Public Procurement Bureau was borne out of her personal desire to ensure an end to "the unbridled pillaging of the public treasury" through bogus contracts—a task for which, due to her strong conviction, she was willing to "literarily lay down her life" to achieve. 
Leaders' Pragmatic Approach to Public Leadership

All the leaders interviewed had a highly developed sense of contextual analysis for public leadership. Learning to work with people by building logical mental models from underlying situational factors help these leaders to be effective, even in difficult organizational environments. The leaders interviewed shared experiences that required them to be adaptable, resourceful, entrepreneurial, and effectively communicative with different stakeholder groups to achieve results.

Leaders also demonstrated a good understanding and appropriate use of transactional leadership for delivering results. Most of the leaders utilized innovative solution designs in resource mobilization and were aware of the need to build institutions around reforms.

\section{Innovation and Creativity in Leadership}

All interviewed leaders recalled creative and innovative solutions to complex challenges in the public domain.

Amaka makes the case most succinctly when she remarked that "I didn't go into the place (public sector appointment) with a model", but that what "turns out to be my agenda actually defines itself after careful analysis of my surroundings". Rather than define the agenda in her experience, she realized that the agenda defined her. Therefore, her leadership was molded to fit the nature of specific challenges she faced while in office. In this she related her experience in attempting to reform the elite public school (Unity Schools) system by inviting private participation in funding schools. This was met with such stiff resistance from the most unlikely quarters_old students' associationsand she all but abandoned her original proposals in favor of a more acceptable model. 
This was similarly captured in Aminu's accounts of a situation during his tenure in office where he was "open about the tactics and strategies but very clear on the end goals", He adopted an approach that views reform as being a result of several "incremental changes" and not a revolution, where massive disruptions to incentive systems appear to be introduced at once. He described how he carries out an analysis of "underlying incentive gains/losses" among specific stakeholders to negotiate how his desired outcomes are achieved. In an instance, he was willing to allow even the "losers" in his reform actions to help articulate the strategy in his education infrastructure reform.

In his experience, by recognizing the loss/gain models in the reform, he approaches reform actions in a manner that is more likely to deliver enduring results than when you don't want to negotiate, concede, or even bring other people to the table to say this is the agenda. How do we go about it? By involving the stakeholders (including those that might suffer losses if the reform succeeds) in delivering the reform, he believes this reduces their capacity to undermine the reform.

Binta recalled her first impressions on the job in her capacity as a minister and how she came to accept her gut feeling about the significance of context and the assignment. In her case, in order to succeed, she had to overcome the challenge of having to create a conducive environment to deliver. She recalled having to "almost have an island on an island" in the ministry where she was assigned when she realized the "systems weren't functioning" and demands were being made in governance that she wasn't able to accept. This made it difficult to deliver reforms unless, as she puts it, "You have to create the environment within the system". 
She also referred to similar experiences by other successful colleagues in the public sector. According to her, this approach was in following the advice from a former Central Bank of Nigeria (CBN) governor who was very successful. She remembered a conversation she had with him:

I asked him..."How did you succeed?" and he said, "Well, I have come to the conclusion that I cannot operate the CBN. So what I've done is to create an office within an office to deliver"... and then he was able to deliver, because he was successful.

In her view, and in all cases in which she has found herself in leadership positions within the public arena, it has not been an enabling environment. She had used her training and experience to, in her words, "Provide a framework that I can deliver". This is because what's important to her is to "get the goods to the destination and to do it the right way".

Nnenna recounted her experience with managing the infrastructure component of the debt relief portfolio with the National Assembly, where she knew that at the point in time, constituency projects were corrupt. However, when she came to lead the unit with support of a president who didn't want them to be corrupt, she "sat down with the leadership of the National Assembly and worked out a framework". She admitted that in order to "get everyone to conform to a budget", she had to overcome hurdles regarding "which contractors we should choose or whether we should give money to this or that person”.

According to her, once the framework was developed with input from the stakeholders, the team she led was able "to cajole people into that framework". Setting up the framework required trade-offs. For her, it was a process of constantly maneuvering, 
and in maneuvering you have to make compromises. It meant having to make adjustments to your plans and processes to ensure that even those who do not share your vision are able to support the reforms, because you "give people something for you to get something"-and by "something", it means not giving money (bribes), but "other incentives that makes them look good in the public domain".

In Onyekachi’s experience, he recalled setting up a previously non-existent mechanism through a process design that involved contextual analysis. He believes this derives support from his "simple philosophy of creating value", and that in "every situation where we have problems, there will always be solutions". He further reasons that the solution was always something given to him basically by virtue of his ability to "look at context and our environment". This enabled him to design an instrument that would check any kind of behavior that needed changing, and so "it needed to be an instrument that looked at incentives as well as sanctions".

For instance, in the case of leading public procurement reform, he realized that the reforms needed to "provide an incentive so that people want to comply with laid down rules", because the original system was not a rules-based environment. Thus, it was clear that "people obeyed the rules in the breach", but by looking at the context very well, he could design a system that could modify behavior, resulting in the term "due process", meaning that "if you followed due process, then you had complied with all the rules of public procurement", and it is only when you have complied that you now have access to public funds. In fact, without that compliance, you don't have your project approved by the Federal Executive Council, because his team was able to design it in a way that you 
needed to get a due process certificate in order to go forward in the public contracting process.

The foregoing suggests that these leaders were adept at studying their context and know the way to design "a behavior-modifying system", one that attempts to match the ingenuity required to overcome the lack of accountability in the public sector contexts within which they exercised their leadership.

\section{Institution Building Ability}

The interviewed leaders had a focus on entrenching the reforms they initiated. There was a recognition that "it is society that gives legitimacy to an agency at the point it has metamorphosed into an institution". There was also an understanding that institutions are not established by fiat, but through an organic process; as laws and structures build legitimacy over time, they give quality and character to institutions. This institution-building mindset was evident in their recollections of specific decisions while in office.

Binta, as a firm believer in strong institutions, thinks, "Our failing as a country has been because we stretch the institutions so far they stopped performing", and in her view, most of the failings of the country "started when we began to divide ourselves; we divided the capacity available, we spread ourselves so thin we could no longer perform". By this she was referring to the many attempts at restructuring the country in the past 50 years along mainly ethnic lines. Starting from the 1967, Nigeria was subdivided into an initial four regions, and later into 36 states by the 1990 s.

This perception about the decreasing lack of institutional capacity probably informed her approach to institution building and the need "to be a leader that knows she 
has got to deliver in a short time" and simultaneously "root things so that they will live after her". In her role at the Millennium Development Goals (MDGs) office, she ensured that the program can continue after she left by setting up a mechanism with the National Assembly to embed MDG requirements in the budget process.

This worked to a large extent in making public agencies take ownership of the MDGs. She also put "a certain level of checks and balances", meaning that in terms of institutions carrying it on, her predecessors can find some organizational memory to provide support for the future. In her words, "It was more or less saying these are good things that you can do, and you can do them well or you can do them badly". However, you have a rich history of practice to leverage for developing the agency further.

The same view was shared by Nnenna when she relayed her experience in leading reforms at her agency. She recollects having "to design it (the new processes she initiated) in a kind of way that was individual neutral, it was systemic". By building a "team of competencies that had objective metrics", there was a basis upon which they were able to assess what a compliant revenue regulatory and monitoring process would look like. This, according to her, was also targeted at "minimizing the role of individual officers" to the extent that the resulting process ensured a lower level of individual subjectivity as the basis for making the tax evaluation decision. She further opined that "In "the end, the lower the level of individual involvement in tax assessment, the better for us". Therefore, when we would generate our assessments, it was a value-neutral outcome which strengthened the credibility of the process and the institution as a whole.

Onyekachi had a similar approach in his attempt to reform the National Football League. He was constrained by the implications of the Federation of International 
Football Associations' (FIFA) statutes regarding National Football Federations, and yet had to institutionalize new funding models for the sport. He recollected how this was accomplished: "That was the only way we could reconstitute the Federation to accommodate private sector funding in a transparent manner that was needed to support the development of the sport".

The situation was complicated because the leadership of the Football League gets into office by election by the Chairmen of Federation of Football Associations across the states. It also means the minister cannot unilaterally remove them from office because, based on FIFA statutes, they were elected and not appointed as the minister was. They therefore relate with appointed cabinet ministers, if not as an equal, then as someone who has even an inferior mandate than theirs, because (1) He was elected while ministers are appointed and (2) they have a transnational affiliation that cabinet ministers don't have. This makes it extremely difficult to remove them from office for ineffectiveness.

However, in this case, it was obvious that instituting reforms for the football league by changing its governance structure cannot succeed and become embedded if there was no change of leadership. He recalled thinking, 'If we did not get rid of them, we would not make progress.' He therefore went about trying to obtain his 'authorization to implement change" through enlisting the state chairmen of football associations - the only body that could remove the ineffective chairman and institute a new order. In his view, the key to institutionalizing the reform lies in obtaining the "the authorization of the people you are working with" that allows you to lead them in a particular direction. A valid authorization to implement change becomes the viable instrument for institutionalizing the change beyond the reform agent. 
Amaka shared her experience at entrenching a culture of transparency in government contracts and procurement. Setting up a mechanism which ensured that public spending must go through a transparent contracting process, backed by relevant laws, passed through the National Assembly. This, for her, was the only way the reform she initiated in curbing the pillaging of the public treasury could be arrested. She galvanized the necessary stakeholder support after due authorization to implement by her principal - the president at the time - to pursue a first ever Public Procurement Act.

The provisions of the act continue to support effective contracting and also help make prosecution of infractions possible. That explains her words in the earlier quote that it is society (through laws and statutes) that ultimately gives legitimacy to an agency at the point it has metamorphosed into an institution, even though decent men and women who enter government as "reform actors must secure the authorization" to make those changes possible.

\section{Leaders as Effective Communicators and Motivators}

Participants were effective at communicating their visions of the public agencies they led, both to internal and external audiences/stakeholders. Interviewed leaders shared experiences of instances when they had to take unusual steps towards achieving group buy-in into reform agenda for better effectiveness. This often required a paradigm shift in the minds of followers about how leaders were expected to reach out to them for support in driving reform initiatives. Effective communication in this regard also entailed an ability to "negotiate with critical stakeholders" for support. 
Onyekachi summed it up by his recollections of his experience in leading the Ministry of Information. The first thing he did was "empower people to be able to talk to him by creating opportunities for them to talk" by going into their offices, sitting there for a few minutes, and sometimes poking fun at the younger ones, basically "making them feel I'm one of them". He was trying to avoid the often-made (by most public-sector leaders) mistake of approaching them (civil servants) with a mindset that tends to exclude them and makes them think that we (political office holders) are the only ones who want change to happen. He believes it is that erroneous attitude/mindset that is responsible for the high rate of failure in public-sector reform, because they (civil servants) also "have the capacity to conspire against us and make us fail".

In a similar vein, Aminu related his first experience at being a chief executive in the public service. As a state commissioner, he brought in a round table into his office to replace the rectangular meeting table they used before. This was because he curiously observed that, by sitting at the head of the table with the permanent secretary and directors, "Valuable ideas travel along the hierarchy of the table" and may sometimes be distorted or shut down before it gets to him. In his words: "I found that the deputy and assistant directors, even when they had an opinion, will rather whisper it to the director, the director will whisper it to the permanent secretary, then the permanent secretary will say it".

Thus, one day, he called the permanent secretary and explained his need "to benefit from the experience of all". He acknowledged the fact that he felt he is being "denied the full benefit of the experience that all of you have if people cannot talk freely". He further assured the permanent secretary of his willingness to ensure he will 
not "undermine him in any way" and that his goal was to provide an atmosphere where people come to meetings. "I want them to be able to freely express themselves".

The transformation that the next meeting at the roundtable brought was phenomenal. "Even the way they walked changed", he noted. "The way they carried themselves changed; they confidently walked up to me". The impact on morale was noticeable in a few weeks. In Aminu's observations, "Even the people who were closing at $1 \mathrm{pm}$ before, but you won't believe we will be in the office till 10pm!" For him, this was a response that seems to acknowledge that "this person recognized us as human beings and that we have something to contribute". The result was that his state was the first to produce a school census that year. It was obvious that "The staff were motivated beyond the normal call of duty" and Aminu recognized that this was all due to a simple decision to remove barriers to effective communication of ideas across the organization.

Amaka shared a similar scenario in her experience with her new post as the Minister of Environment. She had no prior knowledge of the domain, but she has already built a solid reputation for driving notable improvements in environmental protection and awareness about the challenges to environmental management in the country. Her comments were instructive regarding her approach to building a knowledge base for achieving her goals: "I have lot of experience on how to deliver on an issue, and this is got to do with people, it's got to do with creating an open environment where people can share ideas and perspectives".

Her main challenge was to restore "mindsets that have been abused" by previous administrations and "come back and bring them on track" to thinking in terms of a changed narrative. While this may be difficult, it "is not because of technical competence, 
but because of the way I make them feel about themselves". In her experience, she viewed her role as being responsible for clarifying the road map for the team and providing an enabling environment for the team to function.

Oghene shared a similar experience regarding his principal, Binta, and how she navigated a potentially difficult decision with host communities in the Niger Delta. Being Fulani, her role in the process was deemed to be impossible because of longstanding perceptions and mistrust of northern elite interests in the oil industry and the federal government's handling of its governance. However, because of her people skills, she was able to engender the cooperation of host communities and secured the access for the commencement of much-needed interventions in the area. The intervention was successful to the extent that "she's so much liked and welcomed anytime to Oviani land".

\section{Incidental Theme}

A subtheme that was noticeable, even though rather incidental to the leadership effectiveness of the interviewed leaders appear to be the important role they attributed to their socialization - inclusive of family and early life experiences. Three participants (Binta, Aminu \& Amaka) linked their intrinsic motivation to achieve public good outcomes, integrity and character development to early childhood and family socialization experiences. They acknowledged the role of parental influences (especially fathers) and the family 'upbringing' as being very crucial supporting elements for the context within which they developed these attributes. This is quite instructive as these were three leaders who had evolved from different backgrounds across Nigeria, with the differences expected in their religious and ethnic orientations. 
Amaka recalled her father always stressing to her and her siblings that because he had trained them to be persons of integrity and sound moral character, he (her father) was making her 'wealthy in values'. She remembered he insisted that even though she might not be 'cash wealthy, but we were wealthy in values and dignity'. This resonated in her mind and had served to keep her focus in public leadership arena.

Binta's experience in this regard, was stated quite clearly when she opined that 'what you stand for in your home does influence what you do in the public place'. According to her, good 'upbringing' encompasses the totality of the experiences of early childhood and up to the teenage years. Her stellar leadership has benefited from having a family support system comprising of both the nuclear and extended family members who will not accept anything less than good 'moral discipline' affords. A moral discipline defined by fairness and equity in all her dealings, both in public and private affairs.

A similar view was echoed by Aminu, he recalled that most of the 'wise sayings' of his father helped him to develop into a highly principled individual. He believes that ' $95 \%$ of the things he has done in adulthood have been anchored on what I learnt as a child'. He believes that sound parenting is the key to 'leadership maturity'. In his view, becoming acknowledged as an effective leader with integrity and a good work ethic is a result of the 'sound parenting' he received. This according to him has nothing to do with 'what government says or what government does not say, it's first of all about the basic responsibility of parents'.

\section{Summary}

Three major themes emerged from my interviews with the leaders: (a) their managerial and personal approach, (b) their cognitive disposition to achieving good 
governance outcomes, and (c) their pragmatic approach to resolving leadership challenges.

Leaders' managerial and personal approach was linked to early life and family socialization, which produced firm moral and ethical foundations for leadership roles in later life. Leaders cognitive disposition to achieving good governance outcomes is also connected to early life development as being associated with parental influence and helping to shape personal purpose. The leaders pragmatic approach to leadership, as deployed in solving tough leadership challenges can be viewed as a culmination of their maturation process in the use of self-awareness and how this is related to the demands of their context.

The findings from the interviews and close observations of the leaders in the study supports the impression of leaders having a high level of self-awareness about the demands of their public leadership role(s). They were adept at demonstrating their ability to lead. This ability to be a leader can be viewed as a skill in its own right, and it appears to be the glue that keeps these identified themes in focus as leadership toolkits for effectiveness. 


\section{CHAPTER 5}

\section{SUMMARY AND RECOMMENDATIONS}

\section{Summary}

Nigeria's young democracy has witnessed the emergence of a breed of leaders faced with the challenges of delivering good governance outcomes within the weak institutional environments that were inherited from past military regimes and characterized by a culture of corruption and lack of accountability. These leaders demonstrated an uncanny ability to change the political and institutional landscape of the governance environments bequeathed to the young democratic government by past military administrators. They achieved this by providing good governance outcomes and strengthening the institutions they led.

The goal of this research was to develop a grounded theory regarding how the leadership competencies/qualities exhibited by this new breed of public-sector leaders support the achievement of above-the-norm organizational performance in the public sector, despite the constraints of weak governance institutions within their specified contexts. This was done by seeking answers to the central question of how do these activist leaders exercise leadership in a different way from what is practiced in their governance context. 


\section{Research Design}

The primary method of investigation adopted for this study was a grounded theory approach (Strauss \& Corbin, 1994, p. 273), a general methodology of qualitative research designed to build substantive theory based on the systematic collection and analysis of data.

Data collection was primarily by open-ended narrative interviews with a purposive sample of seven public-sector leaders who had been (a) identified by perceived improvement in organizational performance during their tenure in public office, (b) involved in leadership activism as demonstrated by their use of public office to effect social change within their leadership context, (c) in a public-sector leadership role for a minimum of three years, (d) in leadership at the national and/or subnational levels, and (e) validated by a subject matter expert. In addition, I interviewed four key informants who were either past/present associates/subordinates of five of the leaders interviewed in the study.

\section{Conceptual Lenses}

The study has its conceptual framework drawn from the notions of effective leadership from a personal leadership perspective, as described in the works of the following experts: Greenstein (1979) and Mumford (2006). The effective leadership persona(s) offered by the two experts provided useful insights into the personal leadership attributes that support effective public leadership. These include: (a) a commitment to make an impact on public policy and actual impact on policy, and (b) a clear sense of policy direction by articulating a vision and support for an institutional framework that encourages creativity and nurtures innovation within the public arena 
(Greenstein, 1979). Throughout this study, I was mindful of the points of convergence as well as divergence from these perspectives by Greenstein in my interviews with leaders. Greenstein (1979) provided a review of leadership activism in an executive function to include "a commitment to make an impact on public policy" and actual impact on policy achieved by public-sector leaders as a mark of effectiveness. This required leaders' competence, integrity, and character. Greenstein further argued that a key element of success in public leadership is the ability to develop a professional reputation as a skilled leader.

Mumford (2006) proposed a model of pragmatic leadership as the "exercise of influence by identifying and communicating solutions to significant social problems". Mumford further asserted that as an outstanding leadership style, pragmatic leaders are effective because they help to "create structures to support solution implementation, and demonstrate the feasibility of these solutions". Mumford and colleagues also posited that these leaders use an "analysis of organizational requirements and constraints", a capacity for using "wisdom and perspective taking", in order "to craft viable solutions likely to work within the organizational context".

\section{Findings}

The findings from this study provide insight into the following research question: How do these activist leaders exercise leadership in a different way than what is practiced in their governance context?

The study focused on the experiences of seven public-sector leaders and four key informants (associates/colleagues of participants) who experienced the participants' approach to leadership. The leaders were all within the age range of 45-55 years old; they 
are all university-educated graduates_-some had advanced degrees; and all of the participants had spent an average of $10-15$ years in a professional capacity in private sector organizations before being recruited into the public sector roles they held. They are from the six geo-political zones of Nigeria and provided a rich perspective on their socialization, as well as on their religious orientations in a multiethnic and pluralist society.

The public organizations they led were at national (federal) and subnational levels (state and local governments). They spent a minimum of three years in their position as a public-sector leader (four of the interviewed leaders spent upwards of five to six years; two participants are currently serving in public office-one as a federal minister and the other as a state governor). All were initially appointed into public sector leadership positions, but two of them later secured elective mandates after their appointed roles had expired, while a third participant failed in his attempt to secure an elective position (a senate seat in the National Assembly).

The four interviewed informants were all direct associates/subordinates of a named leader already interviewed in the course of the study. All key informants are educated to degree level and had professional relationships with the leaders. They spent a minimum of two years working together with the named leader in either their public or private sector roles. There was significant congruence between the views expressed about the leaders and the informants' perceptions of the leadership experiences from a follower perspective.

Three major themes emerged from my interviews with the leaders that concerned (a) their managerial and personal approach, (b) their cognitive disposition to achieving 
good governance outcomes, and (c) their pragmatic leadership approach to resolving leadership challenges of weak institutional contexts.

Leaders recalled their use of professional competence, demonstrated integrity in character, and a resilient capacity in their exercise of leadership. They recognized the importance of acquired training and experience as a key requirement of leadership within the public sphere. This fosters a tenacious capacity in adapting to the leadership challenges posed by the complexities of the public sphere in young democracies, which arise from low accountability, corruption, and ethnic nepotism.

Leaders were intrinsically motivated to deliver desirable governance outcomes, even when there were no clearly defined performance goals. Their desire to achieve results was guided by a strong personal value system, developed through family and socialization during their formative years. They also had a high achievement focus in their personal life outlook. Leaders were self-motivated individuals who constantly had a personal conviction for improving the organizations they led.

Leaders reported their use of pragmatic leadership behaviors in the setting and achieving of organizational goals. They recalled being innovative and creative in problem-solving approaches, while engendering inclusive decision-making among team members. They provided opportunities for institution-building towards entrenching change/reform in their organizations and their adaptive capacities were illustrated in their understanding and use of transactional and transformational leadership behaviors in communicating and motivating staff for higher performance.

The study revealed that these leaders were able to achieve higher levels of performance than what was normally expected in their context. This occurred through 
their intrinsic motivation to use their competence, leadership capacity, and strength of character in adapting their leadership behaviors to respond to the complexity of their public-sector context.

\section{Discussion}

Even though these leaders came into public leadership roles from different pathways - appointed or elected - they shared a common "commitment to making an impact on public policy". Over the years, these hitherto politically unknown leaders have developed a reputation as competent leaders whose contributions to institutional building and effectiveness have set new positive standards of leadership performance in Nigeria's public sector.

The leaders were from diverse ethnic or religious backgrounds, as evident in Nigeria's pluralistic religious and ethnic bases. They had formative faith experiences in the two dominant religious (Christian and Islamic) family settings and backgrounds, yet they shared a similar intrinsic motivation and commitment to integrity in leadership. Leading with integrity in a complex and challenging ethical environment was a characteristic of these leaders. Leaders attributed these to their upbringing and family socialization.

It is important to note that the leaders shared very similar pragmatic approaches to their leadership challenges at the different levels of government administration from which they operated-be it local, state, or national levels. Although they used different techniques, it was obvious that they were focused on achieving significant positive outcomes in their approach using their unique contexts as the basis for practical organizational changes for results. 
These important observations from the data were drawn from a "grounded theory" approach. This approach assumed no hypothesis regarding what kinds of experiences, perspectives, and behaviors the leaders might share. Theory-building began only after the first interview and continued throughout the data collection process as new information emerged from subsequent interviews with leaders and key informants.

\section{Resonates with Concepts of Dulewicz,}

Mumford, Boyatzis and Greenstein

The personal leadership attributes of the interviewed leaders echo the larger principles enunciated in the conceptual works of Dulewicz and Higgs (2005), Mumford and Van Doorn (2001), Boyatzis (1982), and Greenstein (1979) on leadership effectiveness. The three major themes that emerged from my interviews with the leaders are: (a) their competence-based approach to leadership, which encompasses elements of their integrity and capacity; (b) their cognitive disposition to achieve good governance outcomes, reflecting their higher levels of self-awareness; and (c) their pragmatic leadership approach to resolving leadership challenges of weak institutional contexts. These will now be discussed below in detail.

\section{Leading with a Managerial and Personal Leadership Approach}

The findings from this study is consistent with recent renewed interest by leadership scholars in the cognitive elements of leadership, and is aligned with the approach enunciated by Mumford, Zaccaro, Harding, Jacobs, and Fleishman (2000, p. 14). Mumford and his colleagues proposed that "effective leadership behavior 
fundamentally depends upon the leader's ability to solve the kinds of complex social problems that arise in modern organizations".

This view is further highlighted by qualitative research, suggesting that a leadership framework combining cognitive, behavioral, personality, and learning factors may be a useful one within which to study leadership (De Vries \& Florent-Treacy, 2002; Gina \& Richard, 2004; Higgs \& Rowland, 2001). These cognitive elements in leadership are increasingly recognized as key determinants of leadership effectiveness. The development of emotional intelligence competency frameworks, pioneered by Daniel Goleman (1996), crystalizes this leadership paradigm and pushes the boundaries of personal leadership and effectiveness.

Recognizing the "soft factors" of leadership and the role of personality characteristics in leadership effectiveness is a view informed by research findings, suggesting that leadership effectiveness is correlated to personal characteristics of the leader (Collins, 2005; Hogan \& Hogan, 2001; Mumford, Zaccaro, Johnson, Diana, Gilbert, \& Threlfall, 2000). Although this may appear similar to the traits theories of leadership, it is a distinct but complimentary leadership development trajectory that is anchored on the competency models of leadership — an offshoot of the contingency school. The competency model of leadership defines competence as the "specific combinations of knowledge, skills and personal characteristics" required for effectiveness in specific leadership domains (Boyatzis, 1982).

The leaders in the study share a common level of education, high level of professional knowledge, capability in various disciplines, strong commitment to personal development, and demonstrated experience in leadership. These suggest that even though 
these leaders come from diverse socialization and ethnic backgrounds, they have developed a set of "relatively small range of skills or competency areas" (Higgs \& Rowland, 2001; Kouzes \& Posner, 1999) specifically suited for achieving results in complex environments as embodied by the Nigerian public leadership context.

In providing a competency profile for effective leadership in varying contexts, Dulewicz and Higgs (2003) extended the use of leadership competencies in constantly changing organizational contexts by identifying the engaging style of leadership. The "engaging" leader style is "based on empowerment and involvement in highly transformational context". The style is focused on "producing radical change through engagement and commitment” (p. 228). Dulewicz and Higgs (2005) concluded by organizing the leadership competencies into three main groups: (1) intellectual, (2) managerial, and (3) emotional competencies. This recognition of intellectual competencies as comprising of three elements-(a) critical analysis and judgment, (b) visioning and imagination, and (c) strategic perspective-makes the case for the use of leadership profiling to suit various specific contexts (p. 108).

Leaders in the study recognized that their education, professional experience, and prior personal leadership development significantly enhanced their competence in handling complex problems that the public sector presents to leaders. One of the leaders alluded to the fact that what she brings to her public leadership is "a combination of good training and experience". Another referred to their class of public sector leaders as “technocrats", a deeply political word in Nigeria's political discourse. Traditionally coined to label brilliant professionals and academics who served in public leadership roles under the military regimes from 1988-1999, and more recently for perceived 
"reformers" and "transformational" leaders who are not mired in the political

mudslinging of party politics. A leader also described the competency requirement of her leadership as having developed a "capacity to intellectually assess problems and process a solution to it".

This point was also supported by the key informants who highlighted pivotal moments where these skillsets were instrumental to the leaders' effectiveness in situations requiring effective leadership. A key informant described his former boss as "a solid individual" with the resilience to solve any problem. In a sense, effective leaders in weak governance contexts are perceived as competent and capable individuals. Competence and capability can be developed through prior experience in other contexts and transferred into the public domain.

The suggestion of a "transferability" of competence from private to public sector roles suggest that these identified leaders are better able to adapt their leadership from one sector to the other, in a way that ensures that the right mix of leadership competencies are imported into their organizational contexts. This understanding is supported by research in skill-based leadership, which has provided evidence that while "knowledge and expertise are commonly held to represent domain-specific capabilities" (Phye, 1990), leadership skills are more generalizable or transferable (Mumford, Zaccaro, Connelly, \& Marks, 2000), and this is based on earlier research that examined the extent to which problem-solving and social skills developed in one setting transfer to other settings (Zaccaro, Foti, \& Kenny, 1991).

According to the model of Mumford et al. (2000), effective leadership, when viewed along these lenses, reflects the leaders' capacity in deploying the appropriate 
capabilities, knowledge, and skills such as "perspective taking" in problem solving as a form of "social cognition". By framing the often ill-defined problems of complex environments in a way that facilitates adaptable solutions, effective leaders work as part of a socio-technical system, and this may explain their above-the-norm performance in weak contexts (p. 14).

Leaders from the research sample recalled experiences where they defined their performance goals, framed solutions, and were willing to adapt their preferred approach to suit their capacity and the capacities of subordinates to implement required solutions. One leader commented that she "needed to design an instrument that would check that kind of behavior (corrupt process in public procurement) and so it needed to be an instrument that looked at incentives as well as sanctions". To further buttress the point, one of the participants stated the same pattern this way - that in essence, "you needed to study your context and to know the way to design a behavior-modifying system. and that's what we did". Another leader shared his decision-making experience by stating that "the solution was actually something given to me basically by virtue of my looking at context and our environment”.

The foregoing appears to reinforce the point that effective public-sector leaders in weak accountability contexts possess the ability to adapt their leadership competence and personal capability in a way that meets the demands of their context more readily.

Adaptability in this sense has been found to be a demonstration of significant cognitive development in the various skillsets needed for leadership effectiveness, and is therefore an integral part of competence-based leadership. 


\section{Leading with a Cognitive Approach \\ Towards Achieving Governance \\ Outcomes}

A second major theme that emerged from this study is the strong intrinsic motivation by leaders to deliver results. This resonates with Greenstein's (1979) leadership "activism" in an executive function. It describes "a commitment to make an impact on public policy" and "actual impact on policy achieved by public sector leaders". Greenstein argued that a key element of success in public leadership is the ability to develop a "professional reputation" as a skilled leader (pp. 584-585).

This view is further supported by research in the area of personality-based leadership, which establishes clear links between leadership effectiveness and the individual personality of leaders (Hogan \& Judge, 2013). In exploring the perceived influence of the individual personality of leaders and how this shaped effectiveness, MacKinnon (1944), in his seminal work on the subject, defined personality as consisting of two elements: reputation - how an individual is perceived by others, and identityhow the individual perceives him/herself (p. 4). While reputation can predict what an individual will do, identity, on the other hand, helps to explain why they do it. Thus, while identity and reputation serve different logical purposes in the study of personality, identity is an important starting point for this study because it offers an explanation as to why these leaders are positive deviants in their low leadership performance contexts.

Leaders were quite emphatic about having a desire to "make a difference" based on their "upbringing and values". For these leaders, it was inconceivable for them to occupy a leadership position with attendant power and leverage without reshaping their organizations for the common good. Leaders expressed an overriding personal conviction 
about their understanding of the essence of public leadership as a means to "improve citizens' lives" through effective policy formulation and implementation. There was an innate desire not to occupy public leadership space without making a positive impact on citizens.

In addition to their personal commitment to making a difference, empirical studies of leadership personality identifies four main categories - integrity, decisiveness, competence, and vision (Hogan \& Kaiser, 2005). Leaders had a reputation for integrity in previous organizational or work contexts of being ethical in their dealings. Key informants expressed their trust in these leaders. They had trust in these leaders and their ability to behave towards subordinates in a way that engenders mutual trust. It is instructive to note that none of the leaders in this study had any allegations of corruption (financial or ethical) levelled against them despite having spent an average of three to five years in public service. They were also mindful of the dangers of nepotism (ethnic and religious) in a multiethnic context. This is a significant achievement in a context infamous for corruption and abuse of office by public officials.

In terms of decisiveness, "the ability to make sound, defensible decisions in a timely way" (Hogan \& Judge, 2013, p. 41; Judge, Bono, Ilies, \& Gerhardt, 2002, p. 767), leaders described their ability to "get things done", "deliver goods to the destination" and ensure that set goals are met. This involves several decision steps starting from problem definition, articulating viable solutions, and successfully implementing solutions to deliver results.

Leaders expressed their motivation for accomplishing significant goals - as a resource for their groups. These confer respect upon the leader and his/her demonstrated 
expertise by showcasing their leader skills and knowledge (Hogan \& Judge, 2013), including "general and crystallized cognitive abilities, motivation, and personality" (Mumford et al., 2000, p. 18). Mumford et al. (2000) further suggest that the effects of this attribute on leader problem-solving and performance are indirect because other complex leader skills and knowledge mediate them.

The leaders in the study had a reputation for being visionaries and were able to frame the future, especially with regards to creative solutions to long-standing problems in their public sector domains. They also facilitated team performance by clarifying roles and responsibilities towards achieving results. In engendering open communication with subordinates, peers, and other significant stakeholders, leaders were able to deliver results by building consensus around solutions. These ensured the buy-in of staff and citizens alike, especially in reform initiatives they implemented in public services.

Taken together, these findings provide support for the contributions of complex cognitive abilities, creative thinking skills, and social judgment skills to the performance of critical leadership tasks by identified leaders. These are key elements of the implicit leadership theory (Offermann, Kennedy, \& Wirtz, 1994).

\section{Leading with Pragmatism}

The third theme that runs through the research is one that can be summed up by Mumford and Van Doorn (2001) regarding the leadership of pragmatism. Mumford specifically posits that:

$[\mathrm{U}]$ nder conditions of crisis, change, and turbulence, the behavior of complex social systems becomes unpredictable. As a result of this unpredictability, not only might new threats and opportunities emerge, but the actions needed to effectively respond to these threats and opportunities will also be ambiguous or unclear, because people lack an understanding of the causes and consequences of these change events. Under these 
conditions, leaders can exercise exceptional influence by engaging in sense-making activities that clarify goals and paths to goal attainment. (Mumford, 2006)

They further argue that it is this "sense-making" or "sense-giving" ability that sets effective leaders in complex environments apart from other types of leaders, because "sense-giving" coordinates stakeholder actions and coordinated action makes outstanding leadership performance possible (Akrivou \& Bradbury-Huang, 2011, p. 997). Pragmatic leaders also "exercise influence by identifying and communicating solutions to significant social problems, working through elites in solution generation, creating structures to support solution implementation, and demonstrating the feasibility of these solutions" (Mumford \& Van Doorn, 2001, p. 279).

In further articulating the essentials of "pragmatic leadership", Mumford and Van Doorn (2001) defined three main steps leaders take in the 'pragmatic' approach. Pragmatic leaders utilize "(a) careful observation of people and social systems to identify needs, (b) objective analysis of the situation to identify key restrictions and intervention points, and (c) develop and implement solution strategies likely to maximize benefit at low cost" (Gardner, 1993, as quoted in (Mumford \& Van Doorn, 2001, p. 282). Leaders in the study shared experiences of situations where they had to "be open to alternative strategies, while being clear about the end goal". Even though participants were handed no templates from which to deliver results, they were able to frame longstanding challenges in a way that made them deliver above-the-norm performance by bringing to bear their cognitive abilities in achieving desired goals.

Pragmatic leaders have a capability for "sense-making" by viewing themselves and their contexts as part of a socio-technical system (Mumford et al., 2000). According to Mumford and Gustafson (2007), this "social cognition" represents a complex set of 
skills that pragmatic leaders use for "problem construction, from which selection and screening of knowledge representations based on past experience is thereafter used to define the nature of the problem structure" (p. 33). This enables leaders to structure their information search in order to select and structure relevant concepts that provide the new understandings that serve as the basis for generating alternative solutions. These solutions are then evaluated for their merits before constructing an initial implementation plan.

Participant leaders were creative problem solvers by applying appropriate mechanisms to 'creating a conducive environment to deliver results.' They recalled having to sometimes create 'an island within an island'-in reference to the fact that they identified working solutions to the inefficiencies within the public sector bureaucracy in order to achieve desired goals in an effective and efficient manner.

The leaders' "sense-making" ability is also linked to the leaders' "dynamics of vision"- a proposition that "outstanding leader performance stems from the degree to which mental models successfully crystallize system goals" (Mumford \& Strange, 2013, p. 130). Pragmatic leaders demonstrate a "capacity for complex and integrative meaning making' as a reflection of their personality organization" (Akrivou \& Bradbury-Huang, 2011, p. 996). A vision not only aims to explain a leader's own view of a future, but also simultaneously articulates and constructs the values, purposes, and identities for various stakeholders.

Resonates with Constructivist Developmental Theory Articulating the leaders' values, purposes, and identities within the realms of the constructive developmental paradigm helps to discern links between the leaders' conceptual frames of reference and capacity to align others in strategic action (Cook- 
Greuter, 1999 as cited in Akrivou and Bradbury-Huang (2011, p. 997)) . This "constructivist developmental" theoretical approach "relies on two key constructs that independently allow for a personal movement from simpler to more complex forms of meaning making: self-complexity/differentiation and self-integration" (p. 997).

This "self-complexity/differentiation" encompasses the individual thought patterns, emotions, and self-concepts that are characterized by the "ability to act amid a web of complex relationships and allows the individual to cope with complex demands faced in the social world" (p. 998). This is reflected in individual intelligence, as well as in the "relational aspects of the leaders' experience". Effective and outstanding leaders have high degrees of self-complexity/differentiation and this is demonstrated in how the "leader's vision translates into sense giving by embracing a variety of conflicting issues, while communicating an understanding of various stakeholder realities". This might explain why these leaders are equipped with the multidimensional self-concept needed for differentiated cognitive and behavioral adaptability in a complex social context that public sector leadership represents.

This entails using more than cognitive abilities in determining appropriate action in a manner that ensures alignment of action and personal value systems in the face of demanding ethical choices. It is a transcendental ability of self-governance emanating from a "process sense of self" (Kegan, 2009). The resulting "sense of groundedness" enables pragmatic leaders to develop "a morality imposed by the self and not in accordance with externally imposed moral values" (p. 999).

Leaders expressed having an 'inner moral compass' tied to their ability to critically question personal behavior and avoid pitfalls of nepotism and corruption 
associated with other public-sector leaders in their context. Additionally, they exhibited a sense of individual accountability to society (others' common good) and this resulted in the capacity to effectively transcend the status quo and initiate social and organizational change. Resulting from these elements of self-integration is a set of behaviors consistent with "leadership for the common good" (Kegan, 1995; Kegan \& Lahey, 2009).

\section{Grounded Theory}

Drawing from the leaders' common experiences, perspectives, and behaviors, I have developed a grounded theory that describes how these activist leaders exercise leadership in a different way than what is practiced in their governance context. Through the collection and analysis of data, I identified categories, patterns, and themes and have developed a "plausible explanation” (Corbin \& Strauss, 2008).

An initial set of interviews led to emerging theories which were later tested and re-conceptualized in relation to further interviews. There were constant, ongoing comparisons among the emerging data which led to adaptations and refinement of emerging theories. This recursive process was the foundation to the grounded theory that follows.

\section{Achieving Effective Public Sector Leadership Performance in a Young Democracy: A Grounded Theory}

\section{Introduction}

In the face of widespread misuse and abuse of executive power, endemic corruption and a pervasive lack of accountability that characterizes young/emerging democracies, there are public-sector leaders who are redefining governance by reshaping the organizations they lead, thereby improving the institutional environments of 
previously declining public agencies. These leaders act as positive deviants in leadership performance and are able to deliver above-the-norm organizational performance and effectiveness, despite weak institutional/governance frameworks in a young democracy.

\section{Proposed Theory}

How do activist leaders exercise leadership in a different way than what is practiced in their governance context? I propose that they are able to deliver effective leadership despite weak institutional/governance frameworks, not by using a specific leadership technique, but rather by manifesting their own personal convictions for achieving results — convictions that emerges from a matured conceptualization of their self-integration process. This expresses itself in a strong commitment to use their cognitive and behavioral competencies in a pragmatic way towards solving the complex problems that the public sector presents in a young democracy—one that lacks strong institutions and accountability frameworks.

The leaders' personal characteristics, understanding of self-concepts, and pragmatic approach to solving leadership challenges in their context empower them to successfully create a compelling personal vision that has a clear ethical framework. They combine these with the capacity to use their social and emotional competencies to achieve results. These leaders are able to transcend the peculiar pitfalls of leadership in their contexts by achieving a high degree of congruence in their notions of self, which they then successfully deploy in making intelligent decisions for the common good through an effective use of social power.

Leaders have self-assurance in their resilient capacity to solve even the most challenging and complex organizational problems. They have acquired a combination of 
educational and experiential competencies in multiple sectors and are able to successfully transfer these competencies into the public-sector arena by identifying and deploying the relevant skillsets from their repertoire of capabilities. Leaders are therefore very confident in their abilities and are self-motivated to use these cognitive skills in their public-sector engagements.

These leaders also believe in the importance of modelling effective leadership as a tool for problem solving and utilize an altruistic approach based on their high degree of integrity and concern for others' wellbeing. This approach focuses on how much leaders are able to integrate their experience into the sense-making and sense-giving experience required to lead in a complex environment for the public good. A high level of selfawareness permeates decision making and inspires consensus among followers toward the achievement of a shared vision.

The leaders' capacity to inspire the followers' learning is substantially enhanced when certain personal characteristics are present. A reputation for competence propels them to set higher standards of achievement for themselves and others. Their emotional and social intelligence enables them to build trust and continually adjust their leadership to maximize effectiveness. Rejection of the common pitfalls of leadership in weak institutional contexts further deepens trust with their followers as leaders openly embrace dialogue and stakeholder consultation. Finally, the leaders' resourcefulness, pragmatism, and imagination help them keep the goal of achieving the common good at the center of their efforts.

They are significantly able to remain fastidious in the pursuit of making a difference in public office by drawing from a deep-rooted combination of a good value 
system and personal motivation. These motivations come from early family upbringings, socialization, education, and good quality career experiences that are pivotal in developing leaders into being result-oriented individuals and creative problem solvers.

\section{Conclusions}

Developing leaders who successfully lead public organizations effectively is the responsibility of many parts of the "ecosystem of public leadership". As leaders are being formed as children, growing into young adults, being equipped for private and public careers, and developing their careers in various organizations and sectors, all parts of "the social system" have major roles to play in developing well-rounded self-concepts in individuals. Indeed, if we want to address the tendencies toward ineffective leadership in public-sector domains, then the whole trajectory of social development has to be considered. How do children get motivated to be conscientious at every task? How does society socialize young adults/citizens into responsible holders of civic responsibility? What notions of self are shared along ethnic and religious divides that promote the common good? How do we reshape the narratives that drive national ethical development?

These questions and the important answers needed to support activist leadership development require a holistic review of social structures. Evidence from the experience of leaders in this study suggests that activist leadership behaviors evolve over the whole life trajectory of these individuals and need nurturing at significant points in their lives. These leaders present a glimmer of hope in young democracies as they may form the nucleus of the emerging set of positive deviants of effective leadership desperately needed to support the development of these societies. 
Those who already demonstrate effective leadership in this context are well poised to raise these questions in the public-sector domain. As the leaders in this study have shown, significant change in the level of public-sector leadership is possible if a critical mass of leaders adopts these approaches.

\section{Recommendations}

While a national ethical rebirth is imperative for public spirited leadership to thrive in Nigeria, there is also the need to revamp leadership development at every level of national life. National policy development institutes and public-sector leadership development professionals will undoubtedly find the increasing need to reduce the impact of poor leadership on the delivery of good governance outcomes for building better societies, especially in weak governance environments where citizens currently bear the brunt of the effects of ineffective leadership.

The findings from this study suggest that the leaders' success does not lie in following specific leadership techniques, but in a combination of factors. These factors constitute the other "parts" - education, skills and competency development, innovation, pragmatism, family socialization and astute political acumen —of the leadership 'ecosystem', and must be considered for their roles in growing more activist leaders who will deliver effective public-sector leadership at all levels of national organization. This calls for a new paradigm in the overall "ecosystem" of leadership development in Nigeria. An ecosystem defined as the combination of all the interactions of specific elements of a complex system of individual leadership development. The leaders in this study appear to have integrated different parts of their personal leadership development into a congruent whole. 


\section{Recommendations for Practice}

Based on the findings of the research study, a number of recommendations could be advanced for activist leadership in Nigeria, as well as leadership of other countries facing similar developmental challenges as Nigeria.

1. Foremost among recommendations for leaders from the research data was that activist leaders have to develop an effective leadership persona, by being competent, innovative, pragmatic, ethical and patriotic. In order to achieve effective leadership persona, a leader has to develop a high level of self-awareness that recognizes the need for continuous development in multiple disciplines of public sector leadership. Activist leaders are adaptable, have a willingness to embrace disparate views and are also flexible, although uncompromising of their values.

2. Activist leadership requires that leaders are developed with a framework that emphasizes a track record of accomplishments. This can be achieved by creating opportunities for leadership capacity development in the public and private sector. Midlevel career opportunities to provide the experience of solving 'real' complex challenges in the public sector should be a part of the national public service institutes' leadership curriculum. The foregoing could be easily achieved if the leaders are constantly assigned real-life challenges that can be implemented in their various public sector departments.

3. The data from the research study suggested leaders are sometimes unaware of key public sector goals in the different agencies they led, and they had to define performance indicators that reflect their individual understanding of the challenges they faced. Senior political leaders would therefore need to incorporate specific development goals and clear performance criteria in the appointments of public sector 
leaders as a matter of policy. The National Planning Commission, as a repository of all national development data ought to actively work with political leaders in ensuring these critical milestones are widely accessible to both citizens and public sector leaders. This will also encourage accountability and a focus on achieving desired developmental goals and targets.

4. Specifically, the findings from the data highlighted the primary focus of activist leaders as being pragmatists in their approach to solving complex leadership challenges. These leaders were able to utilize the resources available to achieve organizational goals in a manner that demonstrate a good understanding of their context. They accomplished success based on perceived leadership integrity and capacity. Leadership training should emphasize specific personal learning in developing integrity and the overall achievement of the common good. An ethical rebirth to tackle the current pervasive focus on parochial interest is of great importance to developing effective leadership in weak governance environments. Current screening of political office holders should include an objective 'integrity check' by the relevant government agencies.

5. The findings from this study suggests that there was very little formal interaction among these activist leaders while they held office. Leaders could have benefited from a peer review system that fosters knowledge sharing and build synergy in approach. A number of leaders operated within the same cabinet era at the federal level and had responsibility for managing portfolios with cross-cutting themes. A peer review mechanism could have benefited the public sector leaders in shaping a more integrated decision-making system. This would be more effective than decisions travelling through 
normal bureaucratic channels. The findings recommend that such a system is needed among public sector leaders as a support system for effective performance.

6. The study also found that activist leaders possessed a resilient capacity for taking on the most daunting challenges in the public sector. This was reflected in their ability to challenge the status quo and raise the level of accountability normally expected in their context. This study recommends that prospective holders of public sector leadership - either through the electoral process or by executive appointments, should endeavor to identify leaders who have demonstrated capacity for grit in tackling 'stubborn problems'. Stubborn problems include some of the longstanding issues that have defied solutions for decades; examples abound in the power, infrastructure, education and health sectors. This requires leaders who have a well-developed capacity for a robust interrogation of the problem, and an uncanny ability to frame both the problem and solutions in a way that makes solutions implementation feasible. Identifying and positioning these leaders in critical sectors of the public arena is invaluable to young democracies as they seek to build or strengthen institutions.

7. A final recommendation for practice is the need for leaders to develop effective communication styles that connects the challenges with the context, in such a way that elicits support for solution pathways. The activist leaders demonstrated that communicating both the problem and the preferred solutions to responsible stakeholders can be an effective means of securing a 'license to operate'. A license to operate implies the enlisting of support from a wide range of actors and has the potential to make or mar effectiveness of outcomes. Developing an effective communication skill is therefore an essential part of activist leadership because it paves the way for enlisting support for 
sometimes unpopular but rational and viable solutions to some of the complex problems in the public sector.

\section{Implications for Long-term Development of Public Sector Leadership}

As a closing point, I offer a few recommendations below drawn from the tangential themes from the findings of this research. Specifically, to address the longterm influence that family socialization may have in shaping activist leadership as part of the ecosystem of leadership development. The 'ecosystem' refers to the whole ecology of leadership development which encompasses the family as its basic unit and the society at large. Following each recommendation, I specify which parts of the system could make a significant contribution.

1. The system ought to teach, encourage, and support leadership formative practices among families, both by empowering adult family members to model leadership in a way that nurtures children and youth in effective behaviors. This could be by regularly rewarding and supporting formative practices for children and youth in the context of civic responsibility, especially in early education curriculum [parents, education policy managers, youth and leadership development practitioners, corporate organizations]. 2. The system ought to recognize that decent formal education and leadership experience provides cognitive skills that may not be available to leaders who do not pursue sufficient educational attainment. These skills are necessary for leading effectively as they equip proteges with cognitive abilities needed to interrogate social problems in a way that aids effective solutions, either by interpreting advice or leading solution development and implementation. While Nigeria does not lack educated leaders, 
there is a need for appropriate consideration of evidence and use of cognitive skills in choosing leaders that both utilize scholarship and practice with basic cognitive capacities in leadership development [key influencers, senior public sector leaders, party leaders, national and subnational legislature, public service leadership development agencies]. 3. The system ought to notice the important role played by senior mentors and key influencers who provided the enabling environment for activist leaders to thrive. It is noteworthy that all the interviewed leaders held public office during a timeframe in Nigeria's democratic development, characterized by a perception of meticulous scrutiny of public sector appointees [key influencers, senior public sector leaders].

4. The system ought to support the cultivation of successful leadership habits that undergird development: creative problem solving, ethical decision making, interest in achieving the common good, willingness to seek knowledge from a range of sources, emotional and social intelligence and adaptability [universities, colleges and vocational centers, camps, religious and community associations].

5. Activist leaders who care deeply about building the nation and have contributed toward building public institutions for effectiveness need to extend themselves into mentorship and coaching for coming generations. To do this effectively, they should endeavor to document their experiences for posterity. Key decision points in Nigeria's national history remains shrouded in mystery and open to conjecture by current generations. This has led to a situation whereby deep-rooted intolerance continues to foster mutual distrust in public-sector, decision-making processes. They should provide needed guidance for the upcoming generation of leaders by stimulating national 
conversations on topical issues in which their experience may provide new narratives for better leadership performance [activist leaders].

6. The system should support current and prospective public-sector leaders' development efforts by (a) continuing to provide opportunities for acquiring leadership skills for tackling Nigeria's peculiar challenges, taking into account the culturally implicit leadership behaviors, (b) guiding emerging leaders in how to develop appropriate selfintegration strategies, and (c) guiding leaders in learning how to analyze and frame public problems effectively while communicating solutions effectively [public service leadership development agencies, national policy development Institutes].

\section{Recommendations for Further Research}

This study raises several questions for further research:

1. What is the significance, if any, of the fact that all the leaders in this study were "recruited" from outside the traditional political party echelons? Their initial entry into public sector leadership roles were all through appointments as "technocrats" rather than election into political office.

2. What are the experiences, perspectives, and behaviors of these leaders when viewed in terms of the behavioral dimensions of leadership personality? For example, how much personality variations exist among the different leaders when subjected to evaluation through the five-factor model? What might a study focused on other developing countries' leaders reveal?

3. Why didn't these leaders struggle with the corruption and ethnic and religious bigotry that is widely noted within the public leadership failure in Nigeria? They all grew 
up and had their formative years in Nigeria, yet are able to transcend this crippling malaise that continues to threaten effective public leadership.

\section{Epilogue}

This study of the experiences of seven public sector leaders and their exercise of leadership has given rise to a grounded theory that seeks to answer the question: "How do these activist leaders exercise leadership in a different way than what is practiced in their governance context?" The theory proposes that they are able to deliver effective leadership despite weak institutional/governance frameworks, not by using a specific leadership technique, but rather by manifesting their own personal convictions for achieving results—convictions that emerge from a matured conceptualization of their self-integration process. It further claims that the leaders' personal characteristics, understanding of self-concepts, and pragmatic approach empower them to successfully create a compelling personal vision that has a clear ethical framework, and the social and emotional competencies to achieve results.

As the leaders in this study have shown, significant change in the level of publicsector leadership is possible if a critical mass of leaders adopts these approaches. This calls for a new paradigm in the approaches towards leadership development. 


\section{APPENDIX A \\ QUESTIONAIRES \\ A. INTERVIEW QUESTIONS FOR ACTIVIST LEADERS}

Interview questions for participants fall into three categories: Introductory, Transition, and Key.

\section{Introductory}

1. I've identified you as an activist leader in Nigeria's public sector context based on evidence from your previous role in . Thanks so much for being willing to meet with me to talk about the study. Let me start by asking just a bit about you. Tell me a bit about your style of leadership.

Probe: In what ways have you gotten involved with public sector leadership before your appointment/election?

Probe: Tell me a bit about your understanding of what public sector leadership entails generally. What has been your focus? What are some of the other public sector roles you had before? How did you decide to accept the challenge of leadership in the public domain? What, in your opinion, motivated you to accept the role?

\section{Transition}

Tell me a bit about your tenure of office. 
Probe: What was your typical day like? What kind of leadership decisions did you face most often in a typical day?

Have there been changes in your leadership style during and after the appointment/term?

Probe: How would you describe your overall learning? What prompted these changes? Follow-up prompts—-friends, family, and neighbors, written information, media messages, medical advice, physical health, personal desire to change.

\section{Key}

1. Which of those mentioned changes was most influential to your development as a leader?

Probe: How would you describe it? What seems to work well? What seems to work less well?

2. Tell me about the things you tried but discontinued; the changes you tried to make but were not successful.

Probe: What behaviors do you observe in your key stakeholders? How are they evident in your engagement? In other ways?

What constitutes effective leadership in your view?

Probe: How would you rate successful leaders in this context? Can you tell me five leadership behaviors you consider important to effectiveness or achieving results, no matter how complex or difficult the role?

What are the most critical elements in making governance work?

\section{Transition}


1. How do your leadership behaviors compare to those of other public-sector leaders you have known? What is similar? What is different?

Probe: What, if any, behaviors seem to you to be most effective in "getting things done" here or elsewhere?

\section{Closing Remarks}

Thank you so much for taking time to talk with me about your experiences in the leadership. It's been truly helpful to hear from you on this topic. Before we wrap this up, I'm wondering if there's anything else you might want to tell me about your thoughts about public sector leadership in Nigeria.

Probe: If anything else comes to mind that you want to share with me, please feel free to give me a call or send me an e-mail (at this point, I give my business card). It's been great to talk with you. Thanks again for your time. 


\section{APPENDIX B \\ INTERVIEW QUESTIONS FOR KEY INFORMANTS}

Interview questions for participants also fall into three categories: Introductory, Transition, and Key.

\section{Introductory}

1. Thanks so much for being willing to meet with me to talk about this study. Let me start by asking just a bit about you. Tell me a bit about your work relationship with

Probe: In what capacity were/did you working/work with _(name of leader)_?

Probe: Tell me some general information about (name of leader) at this organization. How long was your posting at ? Who was the head of the organization at the time? What was his/her focus? What, in your opinion, motivated him/her to act in the way he/she did?

\section{Transition}

1. Tell me a bit about _ (name of leader)_?

Probe: When and where do you meet? What would you tell a best friend or family member about __(name of leader)__?

2. What stands out to you about (name of leader)?

Probe: How would you describe your overall assessment of leadership under (name of leader)? How would you describe the assessment of other colleagues who worked with (name of leader)? 


\section{Key}

1. What do you observe about (name of leader)'s approach while leading at ?

Probe: How would you describe it? What behavior seems to work well? What seems to work less effectively?

2. How would you describe (name of leader), both within and beyond the $?$

Probe: What behaviors do you observe in (name of leader)? How are they evident in (name of leader)'s effectiveness? In other ways?

\section{Transition}

1. How do these behaviors compare to those of other leaders you have known? What is similar? What is different?

Probe: What, if any, behaviors seem to you to be most effective in "getting things done"?

\section{Closing Remarks}

Thank you so much for taking time to talk with me about your experiences in this study. It's been truly helpful to hear from you on this topic. Before we wrap this up, I'm wondering if there's anything else you might want to tell me about your thoughts about (name of leader).

Probe: If anything else comes to mind that you want to share with me, please feel free to give me a call or send me an e-mail (at this point, I give my business card). It's been great to talk with you. Thanks again for your time. 


\section{REFERENCE LIST}

Abah, J. (2012). Strong organisations in weak states: Atypical public sector performance in dysfunctional environments. (Doctoral dissertation), Maastricht University, Boekenplan, Netherlands.

Achebe, C. (1984). The trouble with Nigeria. Oxford, UK: Heinemann.

Adegoroye, G., \& Zealand, W. N. (2006). Public service reform for sustainable development: The Nigerian experience. Paper presented at the Commonwealth Advance Seminar, Wellington, New Zealand.

Afegbua, S. I., \& Adejuwon, K. D. (2012). The challenges of leadership and governance in Africa. International Journal of Academic Research in Business and Social Sciences, 2(9), 141-157.

Agba, M. S. (2012, July 27). Public administration, governance and national development in Nigeria. Paper presented at the Korea Association of Public Administration Annual Conference, National University, Seoul, Korea.

Agho, A. O. (2009). Perspectives of senior-level executives on effective followership and leadership. Journal of Leadership \& Organizational Studies, 16(2), 159-166. doi:10.1177/1548051809335360

Ake, C. (1966). Charismatic legitimation and political integration. Comparative Studies in Society and History, 9(1), 1-13.

Akrivou, K., \& Bradbury-Huang, H. (2011). Executive catalysts: Predicting sustainable organizational performance amid complex demands. The Leadership Quarterly, 22(5), 995-1009.

Ancona, D., Malone, T. W., Orlikowski, W. J., \& Senge, P. (2007). In praise of the incomplete leader. Harvard Business Review, 85(2), 92-100.

Ashworth, R. E., Boyne, G. A., \& Entwistle, T. (2010). Public service improvement: theories and evidence. New York, NY: Oxford University Press. 
Avolio, B. J., Walumbwa, F. O., \& Weber, T. J. (2009). Leadership: Current theories, research, and future directions. Annual Review of Psychology, 60, 421-449.

Bahnareanu, A. (2012). Leading change in the public arena. Anale. Seria Stiinte Economice. Timisoara (18), 585-591.

Bass, B. M. (1997). Does the transactional-transformational leadership paradigm transcend organizational and national boundaries? American Psychologist, 52(2), 130-139.

Bass, B. M., Avolio, B. J., Jung, D. I., \& Berson, Y. (2003). Predicting unit performance by assessing transformational and transactional leadership. Journal of Applied Psychology, 88(2), 207-218.

Boyatzis, R. E. (1982). The competent manager: A model for effective performance. New York, NY: John Wiley \& Sons.

Boyne, G., \& Dahya, J. (2002). Executive succession and the performance of public organizations. Public Administration, 80(1), 179-200.

Breckenridge, J., \& Jones, D. (2009). Demystifying theoretical sampling in grounded theory research. The Grounded Theory Review, 8(2), 113.

Burns, J. M. (1998). Transactional and transforming leadership. In G. R. Hickman (Ed.), Leading organizations: Perspectives for a new era (pp. 133-134). Thousand Oaks, CA: SAGE Publications Inc.

Charmaz, K. (2006). Constructing grounded theory: A practical guide through qualitative research. Thousand Oaks, CA: SAGE Publications Inc.

Chemers, M. M. (2000). Leadership research and theory: A functional integration. Group Dynamics: Theory, Research, and Practice, 4(1), 27-43.

Ciulla, J. B. (2004). Ethics and leadership effectiveness. In J. Antonakis, A. T. Cianciolo, \& R. J. Sternberg (Eds.), The nature of leadership (pp. 302-327). Los Angeles, CA: Sage Publications.

Collier, P. (2007). The bottom billion: Why the poorest countries are failing and what can be done about it. New York, NY: Oxford University Press.

Collins, J. (2005). Level 5 leadership: The triumph of humility and fierce resolve. Harvard Business Review, 83(7), 136. 
Cook-Greuter, S. R. (1999). Postautonomous ego development: A study of its nature and measurement. (Doctoral dissertation). Harvard University, Cambridge, MA.

Cooper, J. F., \& Nirenberg, J. (2012). Leadership Effectiveness. In Encyclopedia of leadership. Thousand Oaks, CA: Sage.

Corbin, J., \& Strauss, A. (2014). Basics of qualitative research: Techniques and procedures for developing grounded theory. Thousand Oaks, CA: Sage.

Creswell, J. W. (2012). Qualitative inquiry and research design: Choosing among five approaches (Kindle ed.). Thousand Oaks, CA: Sage.

Day, C., Harris, A., \& Hadfield, M. (2001). Challenging the orthodoxy of effective school leadership. International Journal of Leadership in Education, 4(1), 39-56.

De Vries, M. F. K., \& Florent-Treacy, E. (2002). Global leadership from A to Z: Creating high commitment organizations. Organizational Dynamics, 30(4), 295-309.

Dhar, U., \& Mishra, P. (2001). Leadership effectiveness: A study of constituent factors. Journal of Management Research, 1(4), 254-266.

Dulewicz, V., \& Higgs, M. (2003). A new approach to assessing leadership dimensions, styles context. Competency and Emotional Intelligence Quarterly, 11(2), 224-232.

Dulewicz, V., \& Higgs, M. (2005). Assessing leadership styles and organisational context. Journal of Managerial Psychology, 20(2), 105-123.

Ebegbulem, J. C. (2012). Corruption and leadership crisis in Africa: Nigeria in focus. International Journal of Business and Social Science, 3(11), 221-227.

Eisenstadt, S. N. (1970). Charisma and institution building: Max Weber and modern sociology. The Jerusalem Philosophical Quarterly, 24(1), 1-36.

Eisner, E. W. (1991). The enlightened eye: Qualitative inquiry and the enhancement of educational practice. New York, NY: Macmillan Publishing Company.

Elmuti, D., Minnis, W., \& Abebe, M. (2005). Does education have a role in developing leadership skills? Management Decision, 43(7/8), 1018-1031. doi:10.1108/00251740510610017

Erlandson, D. A., Harris, E. L., Skipper, B. L., \& Allen, S. D. (1993). Doing naturalistic inquiry: A guide to methods (Illustrated ed.). Newbury Park, CA: SAGE. 
Fetterman, D. M. (2010). Ethnography: Step-by-step (3rd ed. Vol. 17). Thousand Oaks, CA: Sage Publications Inc.

Getha-Taylor, H., Holmes, M. H., Jacobson, W. S., Morse, R. S., \& Sowa, J. E. (2011). Focusing the public leadership lens: Research propositions and questions in the Minnowbrook tradition. Journal of Public Administration Research and Theory, 21(Supplement 1), 183-197.

Glaser, B. G. (2004). Naturalist inquiry and grounded theory. Grounded Theory Reader, 19(1), 114-132.

Goethals, G. R. (2005). Presidential leadership. Annual Review of Psychology, 56, 545570.

Goke, A. (2006). Public service reform for sustainable development: The Nigerian experience. Commonwealth Advanced Seminar. Keynote Address. Bureau of Public Service Reforms. Abuja, Nigeria.

Goleman, D. (1996). Emotional intelligence: Why it can matter more than IQ. Learning, 24(6), 49-50.

Göran, S., \& Wood, G. (2005). The serendipity of leadership effectiveness in management and business practices. Management Decision, 43(7/8), 1001-1009.

Gray, C., \& McPherson, M. (2001). The leadership factor in African policy reform and growth. Economic Development and Cultural Change, 49(4), 707-740. doi:10.1086/452522

Greenstein, F. I. (1979). Eisenhower as an activist president: A look at new evidence. Political Science Quarterly, 94(4), 575-599. doi:10.2307/2149627

Grindle, M. S. (1997). Divergent cultures? When public organizations perform well in developing countries. World Development, 25(4), 481-495.

Guyot, J. F. (1962). Government bureaucrats are different. Public Administration Review, 22(4), 195-202.

Hartley, J., \& Benington, J. (2011). Recent trends in leadership: Thinking and action in the public and voluntary service sectors. London, England: The Kings Fund.

Heifetz, R., \& Laurie, D. (1997). The Work of Leadership. Harvard Business Review, 75, 124-135. 
Hernez-Broome, G., \& Hughes, R. L. (2004). Leadership development: Past, present, and future. HR. Human Resource Planning, 27(1), 24-32.

Heshusius, L. (1994). Freeing ourselves from objectivity: Managing subjectivity or turning toward a participatory mode of consciousness? Educational Researcher, $23(3), 15-22$.

Higgs, M., \& Rowland, D. (2001). Developing change leaders: Assessing the impact of a development programme. Journal of Change Management, 2(1), 47-64.

Hogan, R., \& Hogan, J. (2001). Assessing leadership: A view from the dark side. International Journal of Selection and Assessment, 9(1-2), 40-51.

Hogan, R., \& Judge, T. (2013). Personality and leadership. In M. G. Rumsey (Ed.), The Oxford handbook of leadership (pp. 37-46). New York, NY: Oxford University Press.

Hogan, R., \& Kaiser, R. B. (2005). What we know about leadership. Review of General Psychology, 9(2), $169-180$.

Holton, J. A., Bryant, A., \& Charmaz, K. (2007). The coding process and its challenges. In K. C. Antony Bryant (Ed.), The SAGE handbook of grounded theory (Reprint ed., pp. 265-289). Los Angeles, CA: Sage.

Hood, C. (2002). Control, bargains, and cheating: The politics of public-service reform. Journal of Public Administration Research and Theory, 12(3), 309-332.

Hunt, J. (1944). Personality and the behavior disorders (Vol. 1). Oxford, England: Ronald Press.

Jones, B. F., \& Olken, B. A. (2005). Do leaders matter? National leadership and growth since World War II. The Quarterly Journal of Economics, 120(3), 835 - 864. doi:https://doi.org/10.1093/qje/120.3.835

Joyce, P. (2009). Leadership and organisational effectiveness--lessons to be drawn from education? Journal of Nursing Management, 17(4), 494-502. doi:10.1111/j.13652834.2009.01012.x

Judge, T. A., Bono, J. E., Ilies, R., \& Gerhardt, M. W. (2002). Personality and leadership: A qualitative and quantitative review. Journal of Applied Psychology, 87(4), 765780 . 
Jung, K., \& Choi, J. (2011). Institutional leadership and perceived performance: Evidence from the Korean Minister Survey. The Korean Journal of Policy Studies, 26(2), 45-75.

Kaatz, J. B. (1996). City manager tenure stability: A predictive model based on perceived council conflict, leadership effectiveness, and conflict resolution ability.

(Unpublished doctoral dissertation). Northern Illinois University, DeKalb, IL.

Kanungo, R. N., \& Mendonca, M. (1996). Ethical dimensions of leadership (Vol. 3). Thousand Oaks, CA: Sage.

Katzenbach, J. R., \& Smith, D. K. (2015). The wisdom of teams: Creating the highperformance organization. Boston, MA: Harvard Business Press.

Kaufmann, D., Kraay, A., \& Mastruzzi, M. (2009, June 29). Governance matters VIII: Aggregate and individual governance indicators, 1996-2008. World Bank Policy Research Working Paper No. 4978. Retrieved from https://ssrn.com/abstract=1424591

Kaufmann, D., Kraay, A., \& Zoido-Lobatón, P. (2000). Governance matters. Finance \& Development, 37(2), 10.

Kebonang, Z., \& Kebonang, S. (2013). Does leadership matter to development: The case of Botswana, Zimbabwe, Nigeria and Indonesia. International Journal of Politics and Good Governance, 4(4.4), 1-24.

Kegan, R. (1995). In over our heads: The mental demands of modern life. Cambridge, MA: Harvard University Press.

Kegan, R. (2009). The evolving self: Problem and process in human development. Cambridge, MA: Harvard University Press.

Kegan, R., \& Lahey, L. L. (2009). Immunity to change: How to overcome it and unlock potential in yourself and your organization. Boston, MA: Harvard Business Press.

Kekic, L. (2013). The lottery of life: The world in 2013. Retrieved from http://www.economist.com/news/21566430-where-be-born-2013-lottery-life

Kellerman, B. (2012). The end of leadership. New York, NY: HarperCollins.

Kiel, L. D. (1994). Managing chaos and complexity in government: A new paradigm for managing change, innovation, and organizational renewal. San Francisco, CA: Jossey-Bass. 
Kotter, J. P. (1990). What leaders really do. Harvard Bussiness Review, 68(3), 103-111.

Kouzes, J. M., \& Posner, B. Z. (1999). Encouraging the heart: A leader's guide to rewarding and recognizing others (Vol. 133). San Francisco, CA: John Wiley \& Sons.

Leavy, B. (2013). Effectiveness at the top - what makes the difference and why? Strategy \& Leadership, 41(3), 11-19. doi:http://dx.doi.org/10.1108/10878571311323172

Leonard, D. K. (1987). The political realities of African management. World Development, 15(7), 899-910.

Leonard, D. K. (2008). Where are 'pockets' of effective agencies likely in weak governance states and why? A propositional inventory. Retrieved from http://opendocs.ids.ac.uk/opendocs/handle/123456789/4165

Li, J., Tan, Y., Cai, Z., Zhu, H., \& Wang, X. (2013). Regional differences in a national culture and their effects on leadership effectiveness: A tale of two neighboring Chinese cities. Journal of World Business, 48(1), 13-19. doi:10.1016/j.jwb.2012.06.002

Lincoln, Y. S., \& Guba, E. G. (1985). Naturalistic inquiry (Vol. 75). Newbury Park, CA: Sage.

MacKinnon, D. W. (1944). The structure of personality. In J. M. Hunt (Ed.), Personality and the behavior disorders (pp. 3-48). New York, NY: Ronald Press.

Majumdar, S., \& Mukand, S. W. (2010). The leader as catalyst: On mass movements and the mechanics of institutional change. Centre for Competitive Advantage in the Global Economy, 8. Retrieved from http://wrap.warwick.ac.uk/45531/

Manz, C. C., \& Sims Jr, H. P. (1991). Superleadership: Beyond the myth of heroic leadership. Organizational Dynamics, 19(4), 18-35.

Meindl, J. R., \& Ehrlich, S. B. (1987). The romance of leadership and the evaluation of organizational performance. Academy of Management Journal, 30(1), 91-109.

Miles, M. B., \& Huberman, A. M. (1994). Qualitative data analysis: An expanded sourcebook (2nd ed.). Thousand Oaks, CA: Sage.

Mo Ibrahim, F. (2007). 2015 Ibrahim index of African governance. Retrieved from http://www.moibrahimfoundation.org/iiag/ 
Montgomery Van, W. (2003). Public-sector leadership theory: An assessment. Public Administration Review, 63(2), 214 -228. doi:10.1111/1540-6210.00281

Mumford, M., \& Gustafson, S. (2007). Creative thought: Cognition and problem solving in a dynamic system. Creativity research handbook, 2, 33-77.

Mumford, M. D. (2006). Pathways to outstanding leadership: A comparative analysis of charismatic, ideological, and pragmatic leaders. Mahwah, NJ: Lawrence Erlbaum Associates Publishers.

Mumford, M. D., \& Strange, J. M. (2013). Vision and mental models: The case of charismatic and ideological leadership. In Transformational and charismatic leadership: The road ahead 10th anniversary edition (pp. 125-158). Bingley, UK: Emerald Group Publishing Limited.

Mumford, M. D., \& Van Doorn, J. R. (2001). The leadership of pragmatism: Reconsidering Franklin in the age of charisma. The Leadership Quarterly, 12(3), 279-309.

Mumford, M. D., Zaccaro, S. J., Connelly, M. S., \& Marks, M. A. (2000). Leadership skills: Conclusions and future directions. The Leadership Quarterly, 11(1), 155170 .

Mumford, M. D., Zaccaro, S. J., Harding, F. D., Jacobs, O. T., \& Fleishman, E. A. (2000). Leadership skills for a changing world: Solving complex social problems. The Leadership Quarterly, 11(1), 11-35.

Mumford, M. D., Zaccaro, S. J., Johnson, J. F., Diana, M., Gilbert, J. A., \& Threlfall, K. V. (2000). Patterns of leader characteristics: Implications for performance and development. The Leadership Quarterly, 11(1), 115-133.

Nabatchi, T., Goerdel, H. T., \& Peffer, S. (2011). Public administration in dark times: Some questions for the future of the field. Journal of Public Administration Research and Theory, 21(suppl 1), 129-143.

O'Reilly, D., \& Reed, M. (2010). 'Leaderism': An evolution of managerialism in UK public service reform. Public Administration, 88(4), 960-978.

Obama, B. (2009). Remarks by the president to the Ghanaian parliament. Washington DC: Office of the Press Secretary. Retrieved from https://obamawhitehouse.archives.gov/the-press-office/remarks-president-ghanaianparliament. 
Organisation for Economic Co-operation and Development. (1996). Performance management in government: Performance measurement and results-oriented management. Retrieved from https://www.oecd.org/unitedstates/36144776.pdf

Organisation for Economic Co-operation and Development. (2001). Public sector leadership for the 21 st century. Retrieved from http://www.oecd.org/officialdocuments/publicdisplaydocumentpdf/?cote=PUMA/HRM(2 $001) 2 \&$ docLanguage $=\mathrm{En}$

Offermann, L. R., Kennedy, J. K., \& Wirtz, P. W. (1994). Implicit leadership theories: Content, structure, and generalizability. The Leadership Quarterly, 5(1), 43-58.

Ogbeidi, M. M. (2012). Political leadership and corruption in Nigeria since 1960: A socio-economic analysis. Journal of Nigerian Studies, 1(2).

Oke, A. O. (2012). A review of "crucial conversations: Tools for talking when the stakes are high" by Kerry Patterson, Joseph Grenny, Ron McMillan, \& Al Switzler. Journal of Applied Christian Leadership, 6(1).

Oke, A. O. (2013). The media and public accountability in service delivery: A case study of SERVICOM Nigeria. Paper presented at the LIEN International Conference on Public Administration, Nanyang Technological University Singapore.

Osaghae, E. E. (2010). The limits of charismatic authority and the challenges of leadership in Nigeria. Journal of Contemporary African Studies, 28(4), 407-422. doi:10.1080/02589001.2010.512738

Pashiardis, P., Brauckmann, S., \& Muijs, D. (2011). Leadership and organisational performance: From research to prescription? International Journal of Educational Management, 25(1), 45-60.

Perry, J. L., Hondeghem, A., \& Wise, L. R. (2010). Revisiting the motivational bases of public service: Twenty years of research and an agenda for the future. Public Administration Review, 70(5), 681-690.

Peters, B. G., \& Helms, L. (2012). Executive leadership in comparative perspective: Politicians, bureaucrats and public governance. In L. Helms (Ed.), Comparative political leadership (pp. 25 - 55). Hampshire, UK: Palgrave Macmillian.

Piazza, J. A. (2008). Incubators of terror: Do failed and failing states promote transnational terrorism? International Studies Quarterly, 52(3), 469-488. doi:10.1111/j.1468-2478.2008.00511.x 
Pinnington, A. H. (2011). Leadership development: Applying the same leadership theories and development practices to different contexts? Leadership, 7(3), 335365. doi: $10.1177 / 1742715011407388$

Pounder, J. S. (2002). Public accountability in Hong Kong higher education. Human resource management implications of assessing organizational effectiveness. The International Journal of Public Sector Management, 15(6), 458-474.

Rainey, H. G. (1993). Toward a theory of goal ambiguity in public organizations. Research in Public Administration, 2(1), 121-166.

Robbins, S. (1996). Organizational behavior: Concepts, controversies, applications. (7th ed.). Upper Saddle River, NJ: Prentice Hall.

Ruhanen, L., Scott, N., Ritchie, B., \& Tkaczynski, A. (2010). Governance: A review and synthesis of the literature. Tourism Review, 65(4), 4-16.

Schwalb, P. G. (2011). Sustainability leader competencies: A grounded theory study. (Doctoral dissertation). University of Nebraska-Lincoln, Lincoln, NE.

Selznick, P. (1984). Leadership in administration: A sociological interpretation. New Orleans, LA: Quid Pro Books.

Stogdill, R. M. (1950). Leadership, membership and organization. Psychological Bulletin, 47(1).

Stoker, G. (1998). Governance as theory: Five propositions. International Social Science Journal, 50(155), 17-28.

Strauss, A., \& Corbin, J. (1994). Grounded theory methodology: an overview. In N. K. Denzin \& Y. S. Lincoln (Eds.), Handbook of qualitative research (pp. 273-285). Thousand Oaks, CA: Sage.

Summermatter, L., \& Siegel, J. P. (2009). Defining performance in public management: Variations over time and space. Paper presented at the Conference of the International Research Society for Public Management (IRSPM), Copenhagen, Denmark. Retrieved from https://www.alexandria.unisg.ch/53071/1/Defining Performance_IRSPM.pdf

Swart, G., van Wyk, J.-A., \& Botha, M. (2014). African political leadership. In R. A. W. Rhodes \& P. t. Hart (Eds.), The Oxford handbook of political leadership (pp. 659670). Oxford, UK: Oxford University Press. 
Taylor, I., \& Nel, P. (2002). 'New Africa', globalisation and the confines of elite reformism: 'Getting the rhetoric right', getting the strategy wrong. Third World Quarterly, 23(1), 163-180.

Thomas, M. A. (2009). What do the worldwide governance indicators measure. European Journal of Development Research, 22(1), 31-54.

Thomas, V. (2008). Evaluation of world bank support for public sector reform. Retrieved from https://openknowledge.worldbank.org/handle/10986/10621

Thomson, W. (2004). Delivering service in Nigeria: A roadmap. Retrieved from http://servicom.gov.ng/wp-content/uploads/2017/08/Delivering-Service-in-Nigeria-ARoadmap.pdf

Van Wart, M. (2003). Public sector leadership theory: An assessment. Public Administration Review, 63(2), 214-228.

Van Wart, M. (2009). An introduction to leadership and some of the challenges in the study and teaching of it. Public Administration Review. Retrieved from http://citeseerx.ist.psu.edu/viewdoc/download?doi=10.1.1.474.5844\&rep=rep1\&type=pdf

Van Wyk, J.-A. (2007). Political leaders in Africa: Presidents, patrons or profiteers? ACCORD Occasional Papers, 2(1), 1-38.

WorldBank. (2004). World development report 2004: Making services work for poor people. Retrieved from http://hdl.handle.net/10986/5986

WorldBank. (2013). What is a developing country? Retrieved from http://go.worldbank.org/N174APV2T0

Zaccaro, S. J., Foti, R. J., \& Kenny, D. A. (1991). Self-monitoring and trait-based variance in leadership: An investigation of leader flexibility across multiple group situations. Journal of Applied Psychology, 76(2), 308.

Zhihong, Z., Wei, C., \& Xiaoying, Z. (2013). Leadership in public sector: A discussion from theoretical and practical aspects. Canadian Social Science, 9(4), 73-77. doi:10.3968/j.css.1923669720130904.2552 


\section{Akinwumi Oladapo Oke \\ Plot A7, Congress Court Estate \\ Abuja, FCT. Nigeria \\ Phone +234 8034047950 \\ Email akinoke@easydataltd.com}

\section{Professional Experience}

Country Programme Manager, 2016-present

Cordaid, Nigeria Office

Independent Management Consultant, 2013-2016

- Canada Fund for Local Initiatives, Abuja. Nigeria - 2013-2016

- DFID-funded Federal Public Administration Reform (FEPAR) - 2015

Technical Adviser to the National Coordinator SERVICOM, 2013-2015

DFID-funded Federal Public Administration Reform (FEPAR), Abuja

Deputy Operations Manager/ Procurement and Asset Manager, 2008 - 2013

DFID-funded Education Sector Support Program in Nigeria (ESSPIN)

Resources Manager, 2007-2008

British Council, Abuja. Nigeria

Knowledge and Information Centre Manager, 2006-2007

British Council, Abuja. Nigeria

Head, New Project Development, 2004-2006

National eGovernment Strategies Ltd. (NeGSt), Abuja. Nigeria

Clients Services Manager, 1994 -2004

Easydata Resources Ltd.

\section{Education}

Doctor of Philosophy in Leadership

Andrews University, Berrien Springs, Michigan

Master of Business Administration, 2004

Obafemi Awolowo University, Ile-Ife. Nigeria

Post graduate Diploma in Financial Management, 2002

Obafemi Awolowo University, Ile-Ife. Nigeria

Bachelor of Science (Zoology), 1992

Obafemi Awolowo University, Ile-Ife. Nigeria 


\section{Publications}

Oke, A. O. (2012). A review of "Crucial Conversations: Tools for talking when the stakes are high" by Kerry Patterson, Joseph Grenny, Ron McMillan, \& Al Switzler. Journal of Applied Christian Leadership, 6(1).

Oke, A. O. (2013). The media and public accountability in service delivery: A case study of SERVICOM Nigeria. Paper presented at the LIEN International Conference on Public Administration, Nanyang Technological University Singapore. 